\title{
Gas Pipeline Leak Noise Measurements using Optical Fibre Distributed Acoustic Sensing
}

\author{
J M Muggleton ${ }^{1 *}$, R Hunt ${ }^{2}$, E Rustighi ${ }^{1}$, G Lees ${ }^{2}$ and A Pearce ${ }^{2}$ \\ ${ }^{1}$ Institute of Sound and Vibration Research, University of Southampton, Highfield, \\ Southampton SO17 1BJ \\ ${ }^{2}$ AP Sensing UK Ltd., The Square, Basing View, Basingstoke, Hants RG21 4EB \\ *Corresponding author: jmm@isvr.soton.ac.uk
}

No of pages: 38

No of figures: 16

No of tables: 1

No of references: 40

Manuscript submitted to

Journal of Natural Gas Science and Engineering 


\begin{abstract}
Leakage from pipes is a major issue in both the oil and gas sectors, not only in environmental and economic terms, because of wasting important natural resources, but importantly from a safety perspective. Optical fibre technology offers the possibility of continuous acoustic monitoring of pipelines and remote detection of leaks. In this paper we present results from gas leak measurements made on a specially designed, buried pipeline test rig, for which leak energy radiated directly from the leak (orifice noise) dominates over energy radiated from the pipe wall. Measurements of the orifice noise are made using an optical fibre distributed acoustic sensing system as well as conventional geophones. Both the geophones and the optical fibres are shown to be able to detect the orifice noise, particularly when the fibres were located close to the pipeline. Fibre measurements are found to be limited by both high background noise and by gauge length, which limited the upper frequency limit for accurately determining the phase of the ground response. The measurements indicate that the orifice noise sets up Rayleigh waves in the ground, largely contained in frequencies below $100 \mathrm{~Hz}$, the magnitude of which are found to be compatible with predictions from idealised jet theory. The effect of fibre ducting and armouring is also evaluated.
\end{abstract}

\title{
Keywords
}

Leak detection; pipeline; optical fibre; gas; experimental measurements; test rig; distributed acoustic sensing; DAS. 


\section{Introduction}

Pipeline networks are the most economic and safest mode of transportation for oil, gases and other fluid products. As a means of long-distance transport, pipelines have to fulfill high demands of safety, reliability and efficiency. Leakage from pipes is a major issue in both the oil and gas sectors, not only in environmental and economic terms, because of wasting important natural resources, but importantly from a safety perspective. Gas pipelines can traverse thousands of miles often across inhospitable territory in remote areas. Recent highprofile gas leaks see for example [1-3], have highlighted the need for more effective leak detection and monitoring techniques for such pipelines. Acoustic methods predominate in the armoury of available water leak detection methods [4,5] and feature prominently in the range of methods used for gas leak detection [6,7] but, historically, these have been difficult to implement in places where access is limited and conventional sensing using accelerometers cannot be used. Moreover, for very long pipelines, the sheer number of sensors required can preclude the use of a discrete sensing approach.

Optical fibre technology offers the possibility of continuous acoustic monitoring of pipelines and remote detection of leaks [8-10]. Originally used for well monitoring [11,12], and still in its infancy in relation to pipeline monitoring, the technology would benefit considerably from greater knowledge of how the leak noise in a gas pipe propagates both directly into the soil and along the pipe and thence into the soil where it can be detected by the fibre.

Worsley et. al. [13] have used a combination of leak-associated phenomena, including temperature gradients and changes in the surrounding soil, to detect leaks in multi-phase flows in pipelines with a DAS (distributed acoustic sensing) system. Hussels et. al. [14] have examined different ways of applying a DAS fibre to a pipeline, using artificial signals to optimize the measurement parameters. Tanimola and Hill [15] have described a pipeline leak 
detection system using DTS (distributed temperature sensing) and an intruder monitoring based on DAS.

A few investigations have attempted to evaluate the characteristics of water leaks in terms of key parameters, such as leak diameter, flow velocity etc. [16-19]. Hunaidi and Chu [16] found that, for PVC pipes, most of the leak noise is contained in frequencies lower than 50100Hz; Khulief et. al. found similarly [17]. Contrastingly, Papastefanou and colleagues $[18,19]$, studying leak noise in an MDPE test rig, found that useful leak noise data could be present up to several kHz. Moreover, they found that the magnitude of the leak noise spectrum decays with 1/ $\omega$ up until a critical frequency (dependent on leak size and leak flow velocity), thence it decays at a greater rate.

Artificial neural networks have been used with some success to detect gas leaks [20] but, due to the nature of the computational process, neither leak characteristics nor propagation behaviour emerge explicitly. To the present authors' knowledge, the only study examining the characteristics of gas leak noise is that undertaken by Meng et. al. [21], in which they determine that most of the leak noise is contained in frequencies lower than $100 \mathrm{~Hz}$. One study does examine the relationships between leak diameter, gas pressure and leak flow rate [22] but no study has yet focused on the relationship between gas leak noise and these basic leak parameters; nor have any studies examined the subsequent wave propagation in the surrounding soil.

Wave propagation within and radiation from buried pipelines is a multifaceted field of study. Even at low frequencies, several propagation modes can exist, travelling at different wavespeeds, sometimes dispersively. Coupling between the contained fluid and the pipe shell wall often needs to be considered, as does coupling between the pipe shell and the surrounding medium. If the surrounding medium is elastic (as in the case of soil) rather than fluid (as in the case of a submerged pipe) the problem is compounded further by the fact that 
more than one wavetype can propagate in the soil. Add to that, in the case of a leak, that fact that waves will radiate into the soil both directly from the leak and from the pipe wall, as waves propagate along the pipe, and a complex picture emerges. Muggleton and colleagues, see, for example, [23-34], have published extensively on these phenomena, particularly as related to water pipes. However, we have not previously investigated gas leaks.

In this paper we present results from gas leak measurements made on a specially designed, buried pipeline test rig. In this rig, the main pipeline is open-ended and does not contain pressurized gas, the leaks being fed by dedicated small-diameter pipes situated inside the main pipe. In this way, the intention is to minimise the effects of waves radiated into the soil via the pipe wall, thus enabling a study of the effects of the energy radiated directly from the leak alone, sometimes called Orifice Noise (OFN); details of the rig design are expounded further in the main body of the paper.

The paper is organised as follows: section 2 describes the rig design including the pipeline layout, the gas supply system and the fibre measurement system and configuration reference geophones are also incorporated, for comparison; in section 3 the experimental measurements themselves are described, along with how an estimate of the leak flow velocity was made; in section 4, the results are discussed and the effect of key parameters (range, pressure, leak diameter, leak direction and fibre ducting and armouring) evaluated; finally, section 5 presents our conclusions and recommendations for future avenues of research.

\section{Experimental Rig}

The experimental rig has been used previously and has been described in detail in [35]. The salient features, relevant to the testing campaign described in the present paper, are included here for the sake of completeness and ease of reading. 


\subsection{Buried Pipe and Leak Orifices}

The rig consisted of a $30 \mathrm{~m}$ long, $390 \mathrm{~mm}$ diameter steel pipe, was typical of those used for gas transportation (see Figure 1). The original tar coating was removed prior to burying the pipe at a depth of approximately $1 \mathrm{~m} .{ }^{1}$

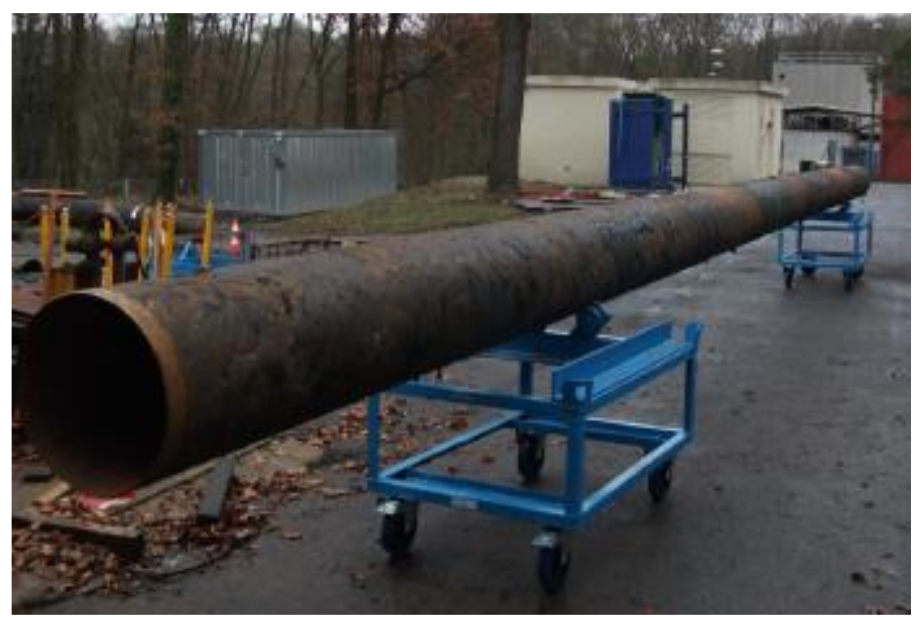

Figure 1

Test Pipe before Burial

Second only to external interference, the EGIG have identified corrosion failure as the main cause of leakage in gas pipelines, with almost all corrosion failures being pinhole (i.e. less than $20 \mathrm{~mm}$ diameter) [36]. On the present test rig, all leakages were simulated by drilling several holes (leak orifices) in the pipe wall; the intention here was to investigate the lower end of the pinhole diameter range, from $1 \mathrm{~mm}$ to $5 \mathrm{~mm}$. As opposed to the real conditions, the pipe was not filled with pressurised gas; instead it accommodated several gas lines feeding the various leak orifices. As discussed earlier, the intention was to thereby investigate the leak noise emanating directly from each leak whilst minimizing waves propagating along the pipe (either in the contained fluid or in the shell) which then radiate into the surrounding ground. As can be seen on Figure 2, there are nine leak orifices on the pipe, enabling

\footnotetext{
${ }^{1}$ Industry practice is such that the maximum burial depth for gas pipes is typically $1 \mathrm{~m}$.
} 
investigation of 3 different leak diameters $(1,3$, and $5 \mathrm{~mm})$ and three different leak directions (upwards, sideways and downwards). Each leak was fed individually by its own dedicated gas line which could be controlled independently; Figure 3 depicts the gas lines at one end of the pipe.
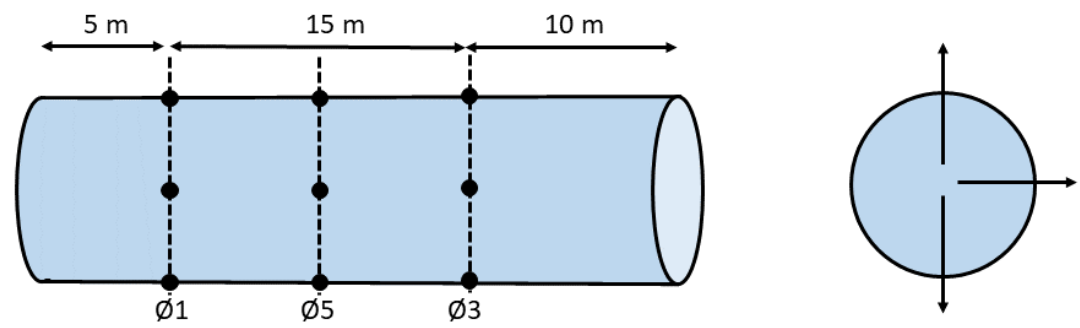

Figure 2

Axial and Circumferential Leak Positions on test pipe

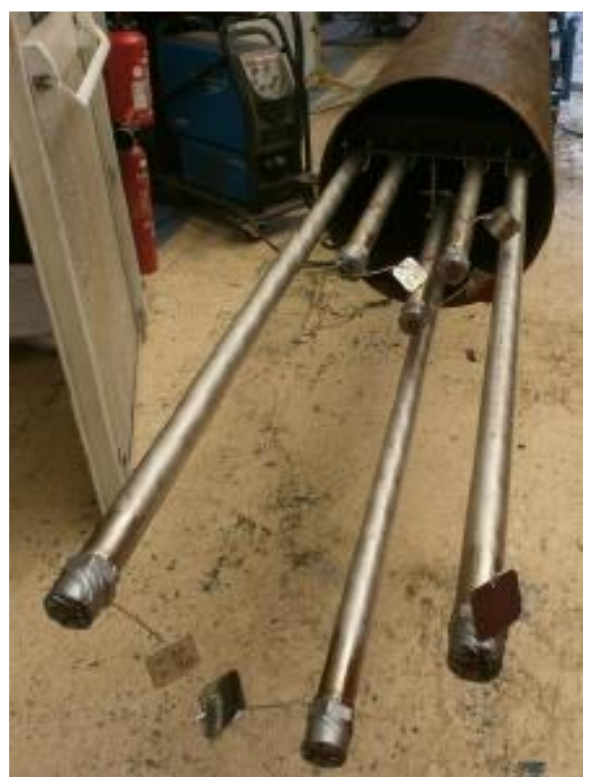

Figure 3

Gas Feed Lines inside Main Pipe

\subsection{Gas Supply System}

The gas supply system is depicted in Figure 4. Gas was stored in racks made up of 18 bottles of 50 litres. The maximum storage pressure was 200 bar. For these experiments, methane was 
used as the fluid contained within the pipelines. Whilst methane and natural gas differ in their exact composition, the fundamental physical processes to be studied here apply equally to both gases. The methane was contained within five of these racks which were simultaneously linked to the pipe system during the trials. One rack was dedicated to nitrogen bottles for purging operations. A pressure regulator was used to achieve desired pressure values during the experimental campaign.

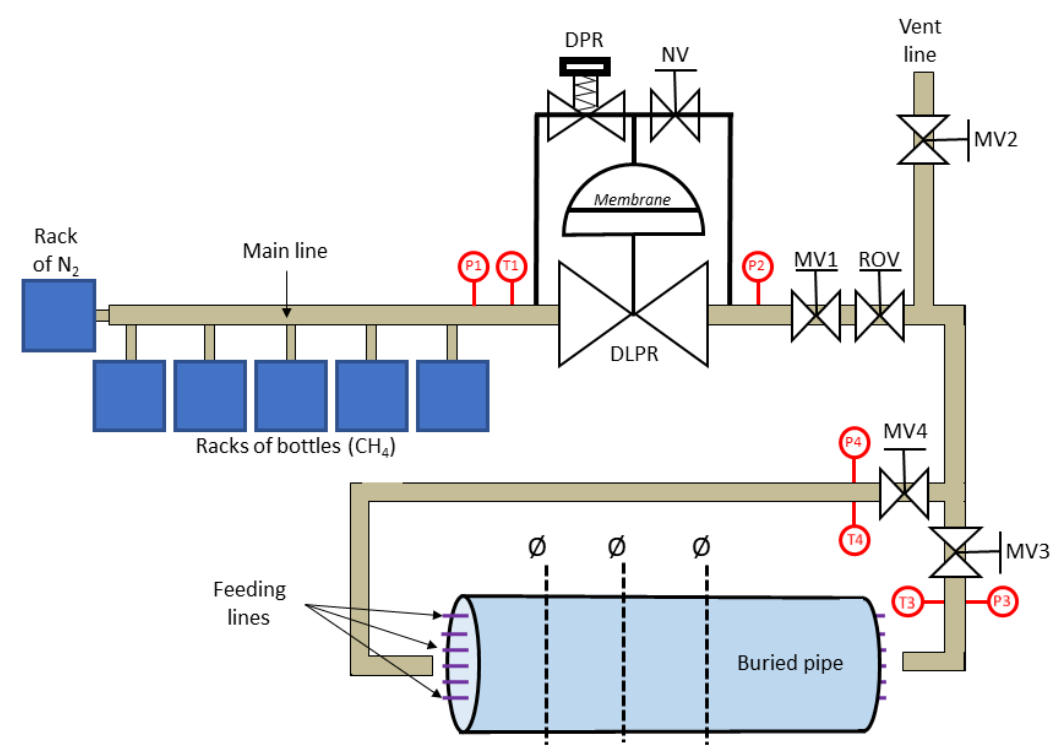

Figure 4

Schematic of Gas Supply System, including Feed Lines and Valves

The main gas supply line was made of 316 stainless steel (nominal diameter 1', , schedule 80). This corresponds to inner and outer diameters of $24.3 \mathrm{~mm}$ and $33.4 \mathrm{~mm}$ respectively. A dome-loaded pressure regulator ("DLPR" in Figure 4) driven by another pressure regulator ("DPR") was used to adjust the gas pressure to the desired value at the leak orifice.

Downstream of the pressure regulator, there was a pneumatic (remotely operated) valve ("ROV") that allowed triggering of the release remotely. Gas was transported through two different branches of the main line depending on which nozzle orifice was being tested: one 
for the $1 \mathrm{~mm}$ and $5 \mathrm{~mm}$ leaks and the other for $3 \mathrm{~mm}$ leak. This was controlled by means of a manual valve located at the entry of each branch (respectively "MV3" and "MV4"). The vent line was only used during the main line purging operations.

The pressure was measured upstream and downstream of the dome-loaded pressure regulator (respectively P1 and P2 in Figure 4) and at the entry of each branch (P3 and P4). The temperature was measured upstream of the pressure regulator (T1) and at the entry of each branch (T3 and T4).

All feeding lines were made of 316 stainless steel with a nominal size of 1" (schedule 80) as for the main supply line. This dimension was chosen so that the surface area of the largest orifice was less than $10 \%$ of the cross-sectional area of the line. This ensured that the main pressure losses would occur close to the orifice and that those occurring along the line could be considered negligible. Specific care was also taken not to impose sharp bends on any of the lines.

\subsection{Optical Fibre DAS System}

Distributed Acoustic Sensing (DAS) systems measure the acoustic and dynamic strain on a fibre optic cable (FOC) using coherent optical time domain reflectometry [37]. Unlike geophones, a DAS system can continuously simultaneously measure vibrational energy along the entire length of the FOC. Current systems can acquire measurements up to $70 \mathrm{~km}$ simultaneously, recording acoustic signals for every 1.28 meters along the length of the cable.

Any disturbance to the FOC at a single point will result in a phase shift for all points downstream of the event location, the technique being widely published [8]. To be able to localise events to specific locations along the FOC, the difference in the phase of the signal is calculated between points separated by a distance, called the gauge length. This has the effect 
of measuring the average strain on the FOC across the gauge length. For this experiment, a gauge length of 10 meters was used; typical of long-range installations.

Due to the method used for measuring the strain on the fibre optic cable, the sampling rate of the recorded acoustic signal is limited by the return time of the light pulse, and hence by the length of the FOC. The theoretical maximum sampling rate can be expressed by

$$
f_{s}=\frac{c_{0}}{2 n L}
$$

where $c_{0}$ is the speed of light in a vacuum, $n$ in the refractive index of the fibre, and $L$ is the length of the FOC. For pipeline monitoring, DAS systems are typically used to monitor large distances. For the results in this experiment to be ecologically valid the sampling rate of the system was set to $1 \mathrm{kHz}$, typical for a long-range detection system.

The AP Sensing DAS system used in this experiment contains a vibrationally isolated coil of fibre within the system, called the reference coil. Due to the isolation, signals recorded on this section of fibre are largely free from environmental noise and act as a reference for the system noise of the measuring process.

\subsection{Optical Fibre Layout and Fibre Positions}

For this test, the FOC was looped back and forth through the pipeline, with each pass buried at a different position relative to the pipe, for a total of nine passes. The cross-sectional layout of the passes is shown in Figure 5 below. 


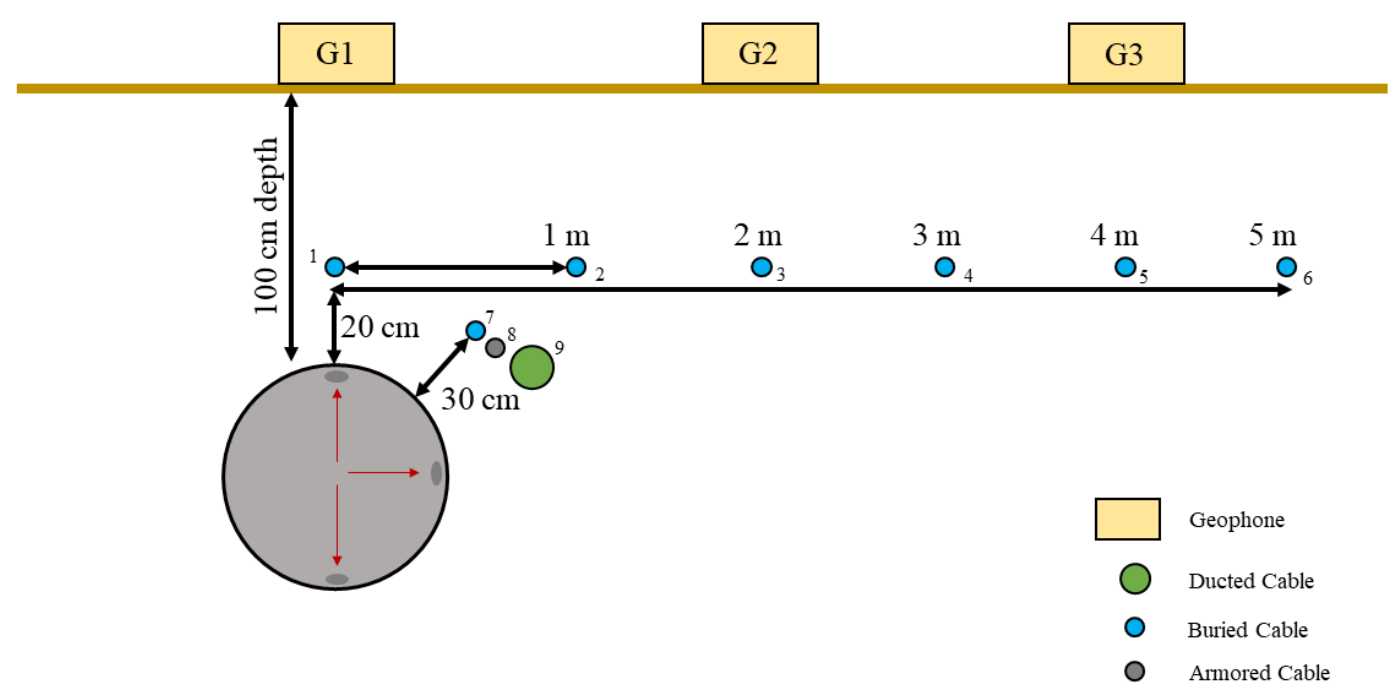

Figure 5

Experimental Measurement Layout: cross section of ground

\section{$2.5 \quad$ Geophones}

As stated earlier, three geophones were incorporated into the measurement system in order that comparisons could be made with the fibre measurements. For each test, the geophones were located at the same axial position as the leak adopted. The lateral position was given as in Figure 5, so that measurements made with geophones G1, G2, and G3 could be compared with fibre positions 1,3 , and 5 respectively. The geophones were oriented such that they measured the particle velocity perpendicular to the pipe axis, i.e. in the L-R direction in the Figure 5. Contrastingly, DAS systems predominantly measure strain axially along the fibre, which in this installation is parallel to the pipe axis. Therefore, whilst qualitative assessments could be made between the two types of measurements, unfortunately it was not possible to make direct comparisons. 


\section{Experimental Measurements}

\subsection{Test Runs}

Leak tests were undertaken to evaluate the effect of gas pressure, leak size and leak direction on the vibration radiated into the soil. Gas pressures of 100 bar down to 10 bar in 10 bar increments were investigated, with one additional value of 5 bar. Typically, export lines run at pressures of approximately 60-100 bar, with distribution networks operating at around 2040 bar. Moreover, EGIG data shows that, in Europe at least, the majority of pipelines operate at above 65 bar [35]. The pressures investigated here are thus representative of all normal operational pressures. As shown in Figure 2, leak diameters of $1 \mathrm{~mm}, 3 \mathrm{~mm}$, and $5 \mathrm{~mm}$ were available, each with leak directions of up, down, and side. In order to test all combinations of the above, a total of 99 test runs would have been required, in addition to background-noise measurements for each run. This was considered to be prohibitively large, given the availability of the test rig and the personnel required to undertake the tests. With that in mind, a set of tests combining appropriate combinations of parameters was chosen, as laid out in the Appendix. Geophone data was acquired for test runs 24 onwards.

\subsection{Data Acquisition and Analysis}

For each testing configuration, optical fibre data was acquired at a $1 \mathrm{kHz}$ sampling rate and 2 minutes of data analysed. Due to the small uncertainty regarding the beginning and end points on the fibre of each fibre position, the centre of each zone was taken as its measurement location for each zone. For the selected gauge length of $10 \mathrm{~m}$, this meant that the measured fibre strain was averaged over $10 \mathrm{~m}, 5 \mathrm{~m}$ each side of the zone centre. The geophone data was sampled at $5 \mathrm{kHz}$, also for 2 minutes. However, the DAS and geophone data were neither sample-locked nor time synchronised, so could not be accurately processed in combination with the fibre data. 
To examine the frequency content of the data, power spectral densities were computed. For some analyses, cross spectral densities between geophone locations or between fibre positions were computed, particularly for the investigation of wavespeeds (related to relative phase). Total vibrational power was found to be a helpful measure, particularly when comparing more than two individual sets of fibre data. For the given test run, for each fibre position, this vibrational power was computed as the sum of the power spectral density over frequency, multiplied by the frequency increment.

$$
P_{t o t z}=\Delta f \sum_{0}^{f_{\max }} P_{z z}
$$

where $P_{\text {totz }}$ is the total power in the measured frequency band $(0-500 \mathrm{~Hz})$ in fibre position $z$, $P_{z z}$ is the power spectral density for the fibre position, $f_{\max }$ is the maximum measured frequency $(500 \mathrm{~Hz})$ and $\Delta f$ is the frequency increment (dependent on the PSD parameters). This was converted to $\mathrm{dB}$ relative to the power measured in the reference coil (introduced in Section 2.3) by

$$
\text { Power }(\mathrm{dB}) \text { relative to reference coil }=10 \log _{10}\left(\frac{P_{\text {totz }}}{P_{\text {totref }}}\right)
$$

\subsection{Leak Flow Parameters}

No direct measurement of the leak flow velocities was made during testing. In this section we examine the flow conditions during the gas leak experiments presented here, via a simple orifice model as depicted in Figure 6. 


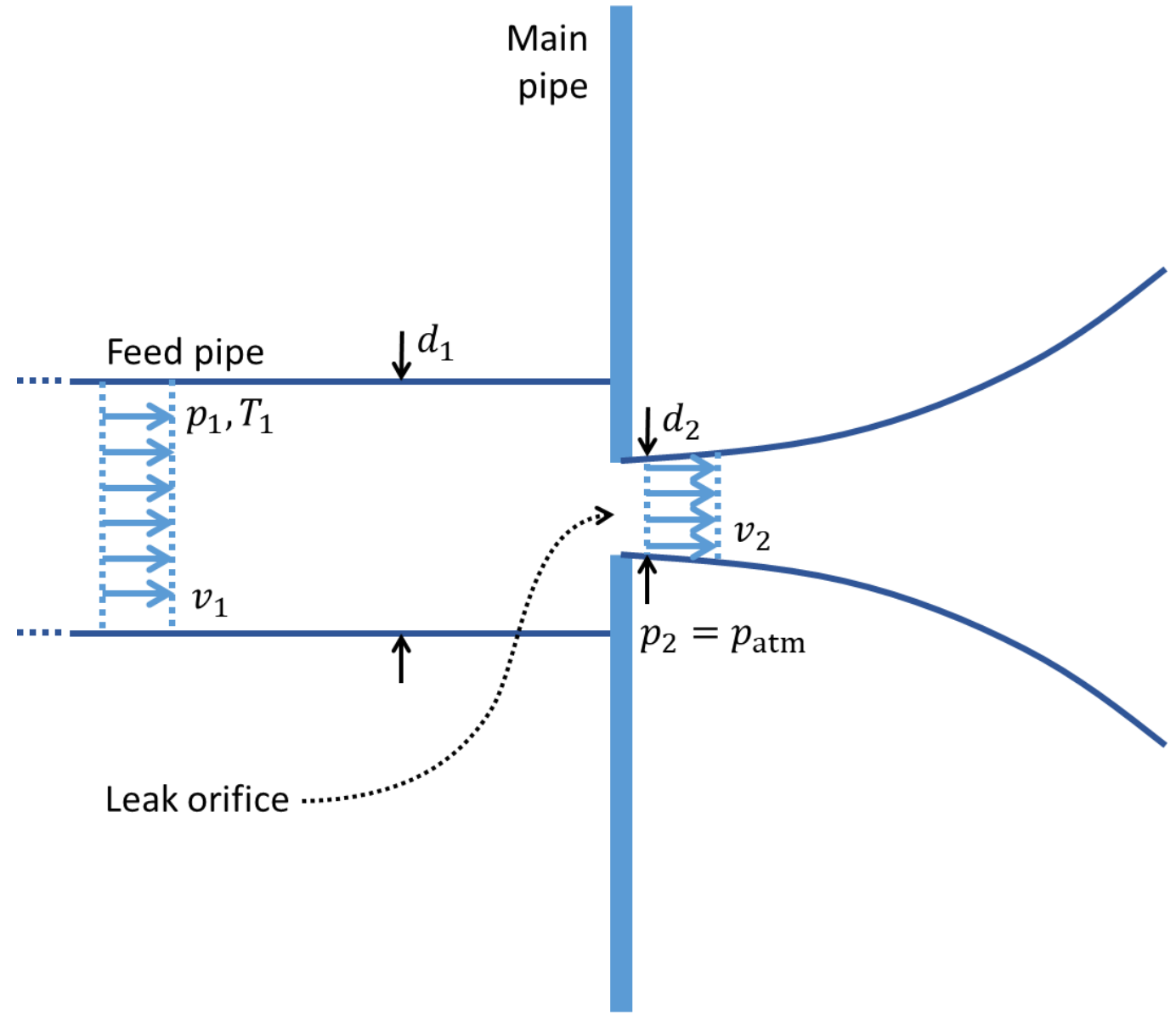

Figure 6

Schematic of Gas Flow through an Orifice

Gas at pressure, $p_{1}$, and absolute temperature, $T_{1}$, flows along the feed pipe, diameter $d_{1}$, at unknown velocity, $v_{1}$. The orifice is of diameter, $d_{2}$; the pressure on the downstream side of the orifice is $p_{2}$; the unknown flow velocity is $v_{2}$. For a compressible fluid, such as the gas considered here, the flow will be choked if

$$
p_{2} \leq p_{1}\left(\frac{2}{\gamma+1}\right)^{\frac{\gamma}{\gamma+1}}
$$

where $\gamma$ is the ratio of specific heats for the gas [38]. For methane, as here, $\gamma=1.32$, therefore the flow will be choked if

$$
p_{2} \leq 0.542 p_{1}
$$


Assuming that the downstream pressure, $p_{2}$, is approximately atmospheric, the flow out of the orifice will therefore be choked for all the test pressures (the lowest of which is 5 bar).

For choked flow, the velocity out of the orifice is given by

$$
v_{2}=C \sqrt{\frac{\gamma p_{1}}{\rho_{1}}\left(\frac{2}{\gamma+1}\right)^{\frac{\gamma+1}{\gamma-1}}}
$$

where $C$ is the flow coefficient (typically around 0.62 , although weakly dependent on the orifice diameter) and $\rho_{1}$ is the (unknown) upstream gas density.

For an ideal gas

$$
\frac{p_{1}}{\rho_{1}}=R T_{1}
$$

where $R$ is the individual gas constant. This gives the flow velocity out of the orifice as

$$
v_{2}=C \sqrt{\gamma R T_{1}\left(\frac{2}{\gamma+1}\right)^{\frac{\gamma+1}{\gamma-1}}}
$$

thus is only a function of the upstream temperature, $T_{1}$.

In terms of Mach number, $M_{2}$,

$$
M_{2}=\frac{v_{2}}{\sqrt{\gamma R T_{1}}}=C \sqrt{\left(\frac{2}{\gamma+1}\right)^{\frac{\gamma+1}{\gamma-1}}}
$$

Temperatures on the pipe rig were measured, as discussed in section 2.2, but were found to vary, in general, by less than $10 \%$ of the absolute temperature between the start and the end of the test run, and by a similar amount between test runs. For the purposes here, it has been assumed that the upstream temperatures are constant. Thus, we assume that the leak flow 
velocity is independent of the gas pressure and the leak diameter (neglecting the weak $C$ dependence). The Mach number for the flow is also independent of the upstream temperature. However, from the above, it can be seen that, for constant leak diameter, the mass flow rate (dependent on the upstream density) will be directly proportional to the gas pressure; for constant gas pressure, the volume flow rate - and hence mass flow rate - will be proportional to the square of the leak diameter.

$$
\dot{m} \propto p_{1} d_{1}^{2}
$$

where $\dot{m}$ is the mass flow rate from the leak.

\section{Results}

Due to the large number of tests undertaken, not all the results are included in this paper; select results are shown to demonstrate particular points or to illuminate phenomena of interest. Except for studying the effects of ducting and armouring, only the $3 \mathrm{~mm}$ and $5 \mathrm{~mm}$ orifices were studied as there were concerns that the leaks from the $1 \mathrm{~mm}$ orifices would be prone to freezing.

\subsection{Revealing the Fundamental Physics: Comparison between Optical Fibre and}

\section{Geophone Measurements}

In order to assess the sensing performance of the optical fibre, measurements at the nearest fibre positions to the geophones were compared with the geophone measurements. With reference to Figure 5, measurements at fibre positions 1, 3, and 5 were compared with the output of geophones G1, G2, and G3 respectively. Both magnitude and phase response have been considered. Power spectral densities were computed for both the fibre and geophone data for one leak scenario (100 bar, 5mm leak, direction up - run 24 in Appendix). In order to study the phase response, cross spectra were computed between fibre positions 3 and 5 and geophones G2 and G3. As the fibres respond to dynamic strain, whereas the geophones 
measure dynamic velocity, a factor of $1 / \omega$ was applied to the geophone spectra, where $\omega$ is the angular frequency. In addition, as both the geophone and fibre measurements were uncalibrated, the geophone data were scaled such that the strain levels measured at fibre position 1 and by geophone G1 were of the same order of magnitude between $10 \mathrm{~Hz}$ and $100 \mathrm{~Hz}$

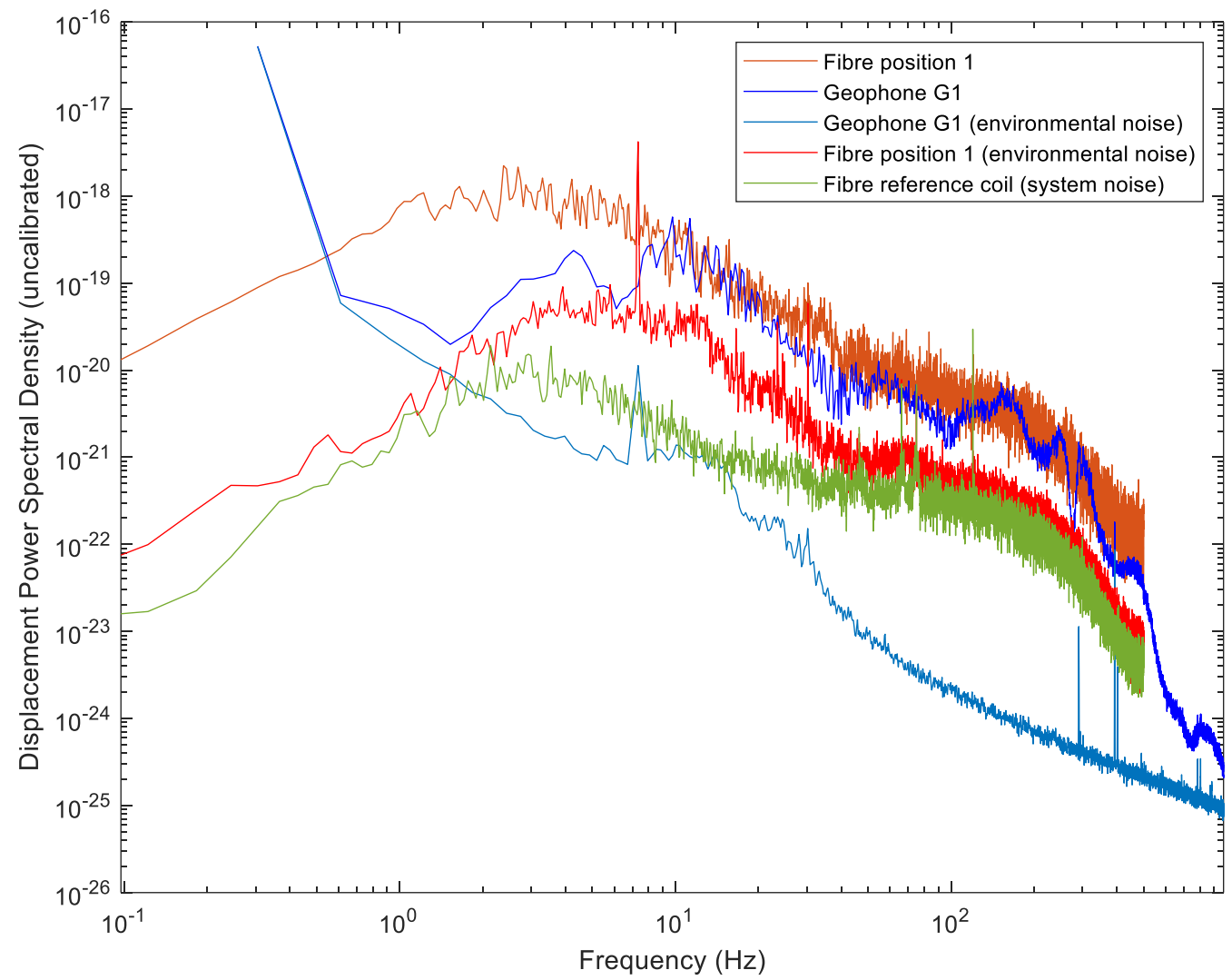

Figure 7

Displacement Power Spectra: Comparison between fibre position1 and geophone G1.

Run 24: 100 bar, 5mm leak, up

Figure 7 compares the magnitudes of the response in fibre position 1 compared with geophone G1; both located directly above the leak location. The figure shows that between $10 \mathrm{~Hz}$ and $500 \mathrm{~Hz}$ (the maximum frequency for the fibre) the geophone and fibre responses are approximately equivalent (brown and dark blue lines). Below $10 \mathrm{~Hz}$ the geophone response 
drops off as expected (due to its low response characteristic below its resonance frequency of $10 \mathrm{~Hz}$ ). Below $1 \mathrm{~Hz}$ the fibre response is likely to be dominated by thermal effects rather than strain. In general, the geophone has a lower noise floor than the fibre with slightly more detail evident in the response, the fibre noise increasing significantly with frequency compared with the geophone; moreover, the background noise levels are much greater for the fibre data. The geophone continues to respond well above $500 \mathrm{~Hz}$; the response of the fibre is unknown above this frequency as it was limited by the sampling frequency. The leak noise measurements are significantly (by more than a factor of 10) above the background noise for both sensors and the reference coil measurement for the fibre at all the frequencies of interest.

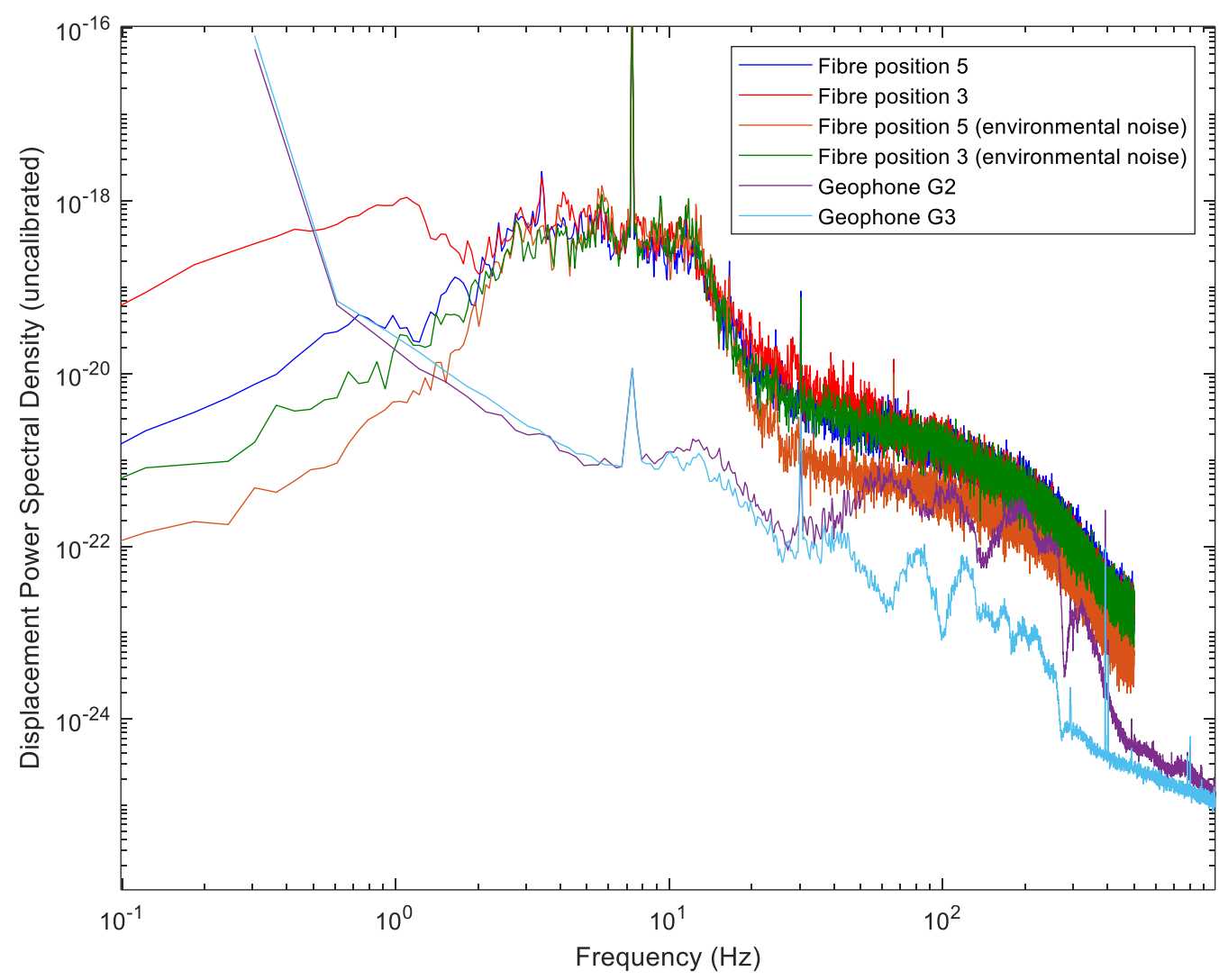

Figure 8

Displacement Power Spectra: Comparison between fibre position 3 and 5 and geophones G2 and G3. 
(environmental noise for the geophones - not included - is similar to that shown in Figure 7)

Run 24: 100 bar, 5mm leak, up

Figure 8 compares the magnitudes of the responses in fibre positions 3 and 5 with those of geophones G2 and G3. Fibre positions 3 and 5 correspond to distances of 2 and $4 \mathrm{~m}$ from the leak position respectively, as shown in Figure 5. Plotted on the same scale as Figure 7, here it can be seen that the magnitude of the geophone-measured response decreases with increased range. Except at very low frequencies, the magnitude of the fibre-measured response in fibre positions 3 and 5 is now, unfortunately, only slightly larger than the environmental noise in those fibre positions. ${ }^{2}$ The low frequency signal for both fibre positions 3 and 5 are higher than the environmental noise, which could indicate a thermal change due to the leak,

Examination of the relative phase between sensor locations reveals additional information. Figure 9 shows the relative phase between geophones G3 and G2. The figure shows that useful phase information can be gained at frequencies up to around $400 \mathrm{~Hz}$. The bi-linear slope of the line demonstrates that two relatively non-dispersive waves, with particle motions aligned L-R on Figure 5, propagate between the geophones (i.e. laterally away from the pipe); the gradients reveal that the wavespeeds of these propagating waves are of the order of $100 \mathrm{~m} / \mathrm{s}$ and $250 \mathrm{~m} / \mathrm{s}$, typical of the Rayleigh and compressional waves respectively in a sandy type soil $[29,34]$. At low frequencies, the Rayleigh wave is seen to dominate, with higher frequencies dominated by the compressional wave.

Measuring relative phase using the DAS system proved to be more difficult. For a fibre gauge length of $10 \mathrm{~m}$, as is the case here, signals are averaged over a $10 \mathrm{~m}$ length of fibre. Here, we examine four possible extreme scenarios:

\footnotetext{
${ }^{2}$ It should be noted, here, that background noise measurements were made in each fibre position, and found to differ significantly. Unfortunately, the specific sources of this noise could not be ascertained.
} 
1. For a wave propagating parallel to the fibres whose particle motion is parallel to the fibres (i.e. a compressional wave, or Rayleigh wave ${ }^{3}$ ), phase information will be lost for frequencies higher than that for which the gauge length is equal to half a wavelength. Thus, for a (compressional) wave propagating at $\sim 250 \mathrm{~m} / \mathrm{s}$, this cut-off frequency is approximately $12 \mathrm{~Hz}$. For a (Rayleigh) wave propagating at $\sim 100 \mathrm{~m} / \mathrm{s}$ the cut-off frequency reduces to approximately $5 \mathrm{~Hz}$.

2. For a wave propagating parallel to the fibres whose particle motion is perpendicular to the fibre direction (i.e. a shear wave), no response will be generated in the fibre.

3. For a wave propagating perpendicular to the fibres whose particle motion is parallel to the fibres (i.e. a shear wave), phase does not change with axial distance, so should be measured accurately by the fibre at all frequencies.

4. For a wave propagating perpendicular to the fibres whose particle motion is also perpendicular to the fibres (i.e. a compressional wave, or Rayleigh waves), again phase does not change with axial distance, but will be largely undetected by the fibre, except that mediated through fibre bending. We consider that it is these waves that have been detected by the laterally-aligned geophones.

\footnotetext{
${ }^{3}$ A Rayleigh wave will also have associated vertically-aligned particle motion.
} 


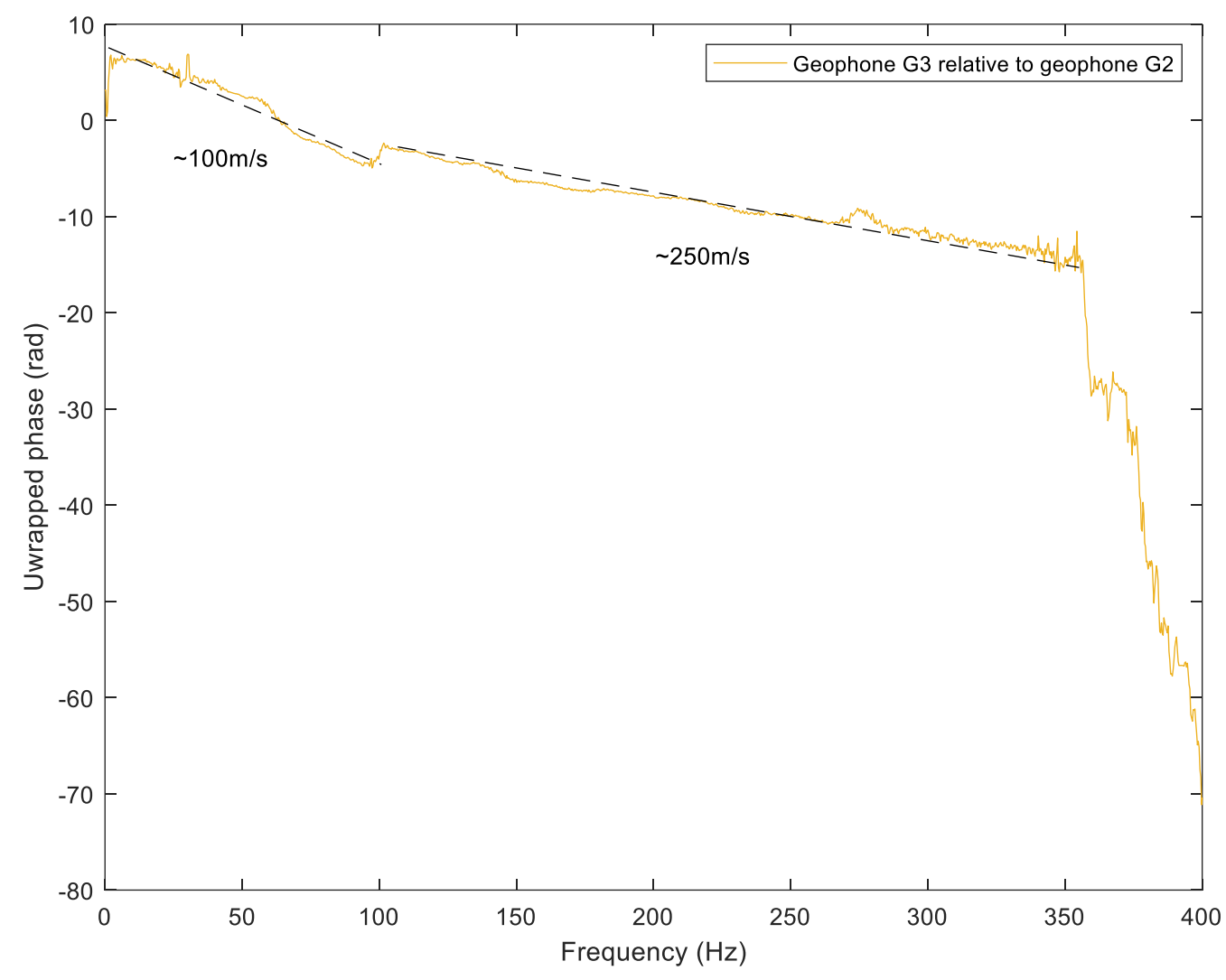

Figure 9

Relative phase in ground surface vibration velocity/displacement measured by geophones Run 24: 100 bar, 5mm leak, up

Figure 10 depicts the relative phase between fibre positions 5 and 3, where a different trend is clearly evident. The figure shows that the measured phase becomes unreliable above about $15 \mathrm{~Hz}$, the expected order of magnitude. The useable bandwidth indicates that there is a phase difference of $2 \pi$ (or zero) between fibre positions 5 and 3 at low frequencies, in agreement with the geophone measurements at these frequencies. It is likely that, at these low frequencies, environmental noise dominates the measured responses which, due to the long wavelengths, will be coherent over the $2 \mathrm{~m}$ sensor spacing. 


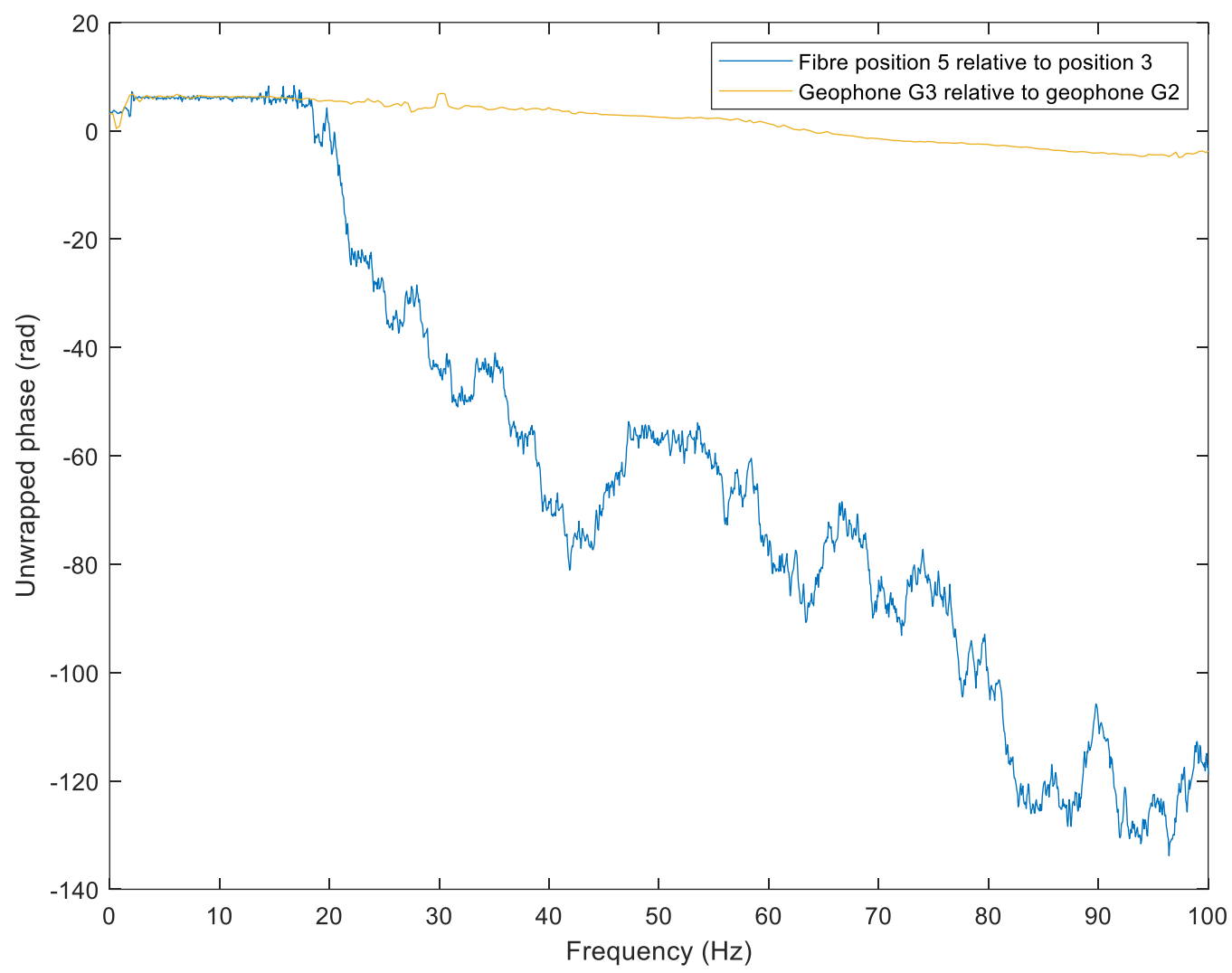

Figure 10

Relative phase in ground surface vibration velocity/displacement measured by optical fibre Run 24: 100 bar, 5mm leak, up

\subsection{Effect of Range}

In order to examine the effect of range on the leak noise signal, two tests in which the leak was directed to the side (Runs 6 and 11, corresponding to $5 \mathrm{~mm}$ and $3 \mathrm{~mm}$ leaks respectively) were chosen. It was considered that side leaks would be the most likely to initiate waves propagating laterally away from the pipe which would dominate the fibre response.

Figures 11 (a) and (b) show the total power vs range for the two runs, along with background noise measurements (no leak) in the same positions. The total power for each fibre position was calculated as described in section 3.2. Also shown are curves assuming Rayleigh wave attenuation (varying with range, $r$, as $1 / r^{0.5}$ ). Ignoring fibre position 1 (at $0.2 \mathrm{~m}$, directly above 
the pipe), it can be seen that, in both cases, the measured response decays with distance approximately as a Rayleigh wave. Given the proximity of the pipe to the ground surface $(\sim 1 \mathrm{~m})$, this is as expected. Rayleigh waves are set up in the ground through the interaction of body waves with a free surface. The influence of these waves, which propagate at approximately the same speed as the shear wave in the ground, extend down to approximately one wavelength's depth. Assuming a shear wave speed of approximately $100 \mathrm{~m} / \mathrm{s}$ the optical fibre will detect Rayleigh waves at frequencies up to around $100 \mathrm{~Hz}$. Figures 7 and 8 for a $5 \mathrm{~mm}$ leak pointing upwards show that most of the measured energy is, indeed, concentrated within this frequency range. ${ }^{4}$

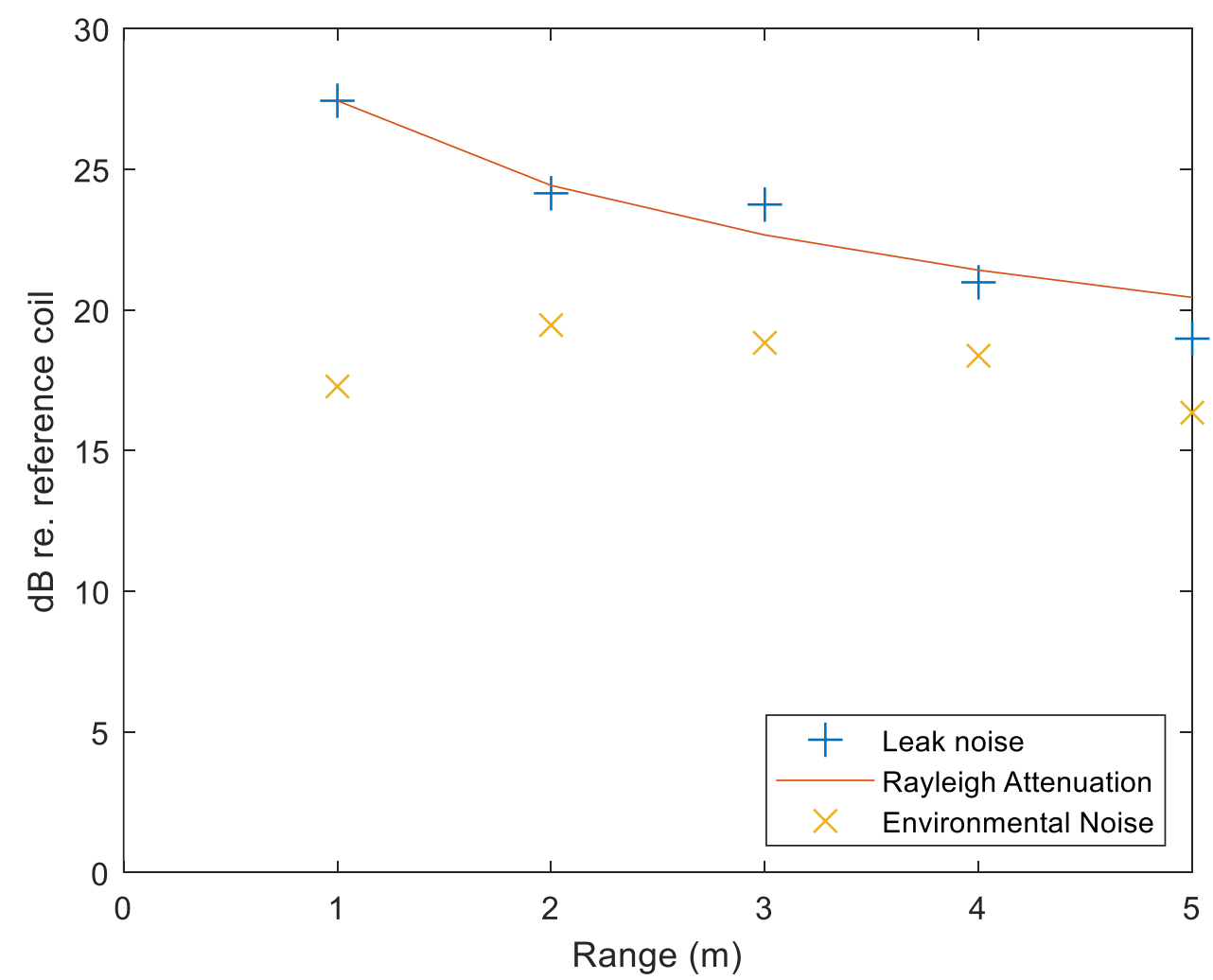

(a)

\footnotetext{
${ }^{4}$ In section 4.4 we will show that the leak diameter has only a small effect on the measured leak noise spectrum.
} 


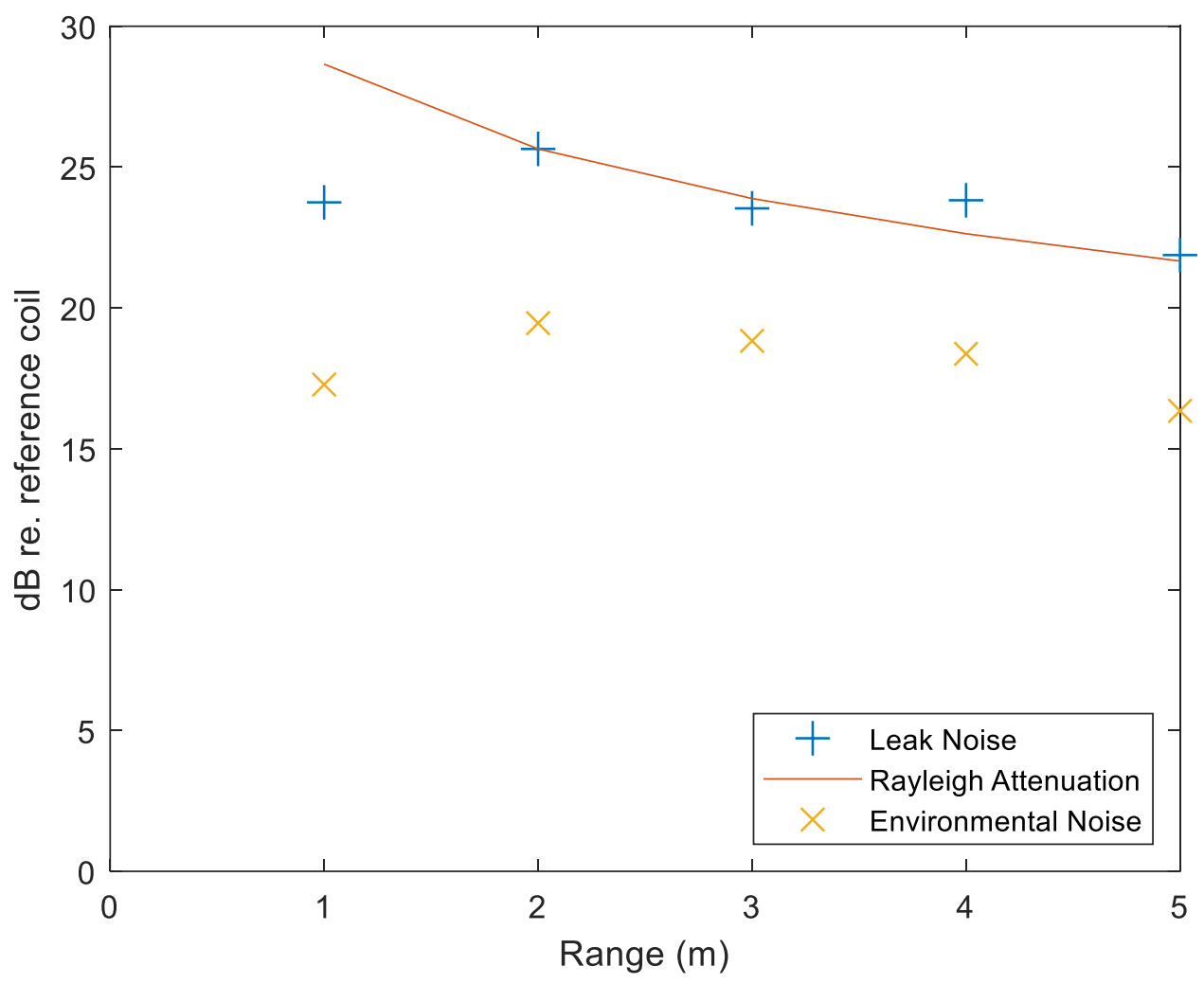

(b)

Figure 11

Total Vibrational Power (in $\mathrm{dB}$ relative to the reference coil) vs Range

(a) Run 6: 100 bar, 5mm leak, side; (b) Run 11: 90 bar, 3mm leak, side

\subsection{Effect of Gas Pressure}

In order to assess the effect of gas pressure, measurements for the $3 \mathrm{~mm}$ side leak at eleven pressures were used: 10 bar to 100 bar in 10 bar increments plus one additional measurement at 5 bar. Co-plotting all eleven power spectra for one single fibre position results in a figure which is difficult to interpret so, as in the previous section, total powers in $\mathrm{dB}$ relative to the reference coil were used.

Figure 12 shows the total vibrational power measured at fibre position 5 ( $4 \mathrm{~m}$ range), plotted against gas pressure. Zero bar represents (two) background noise measurements. 


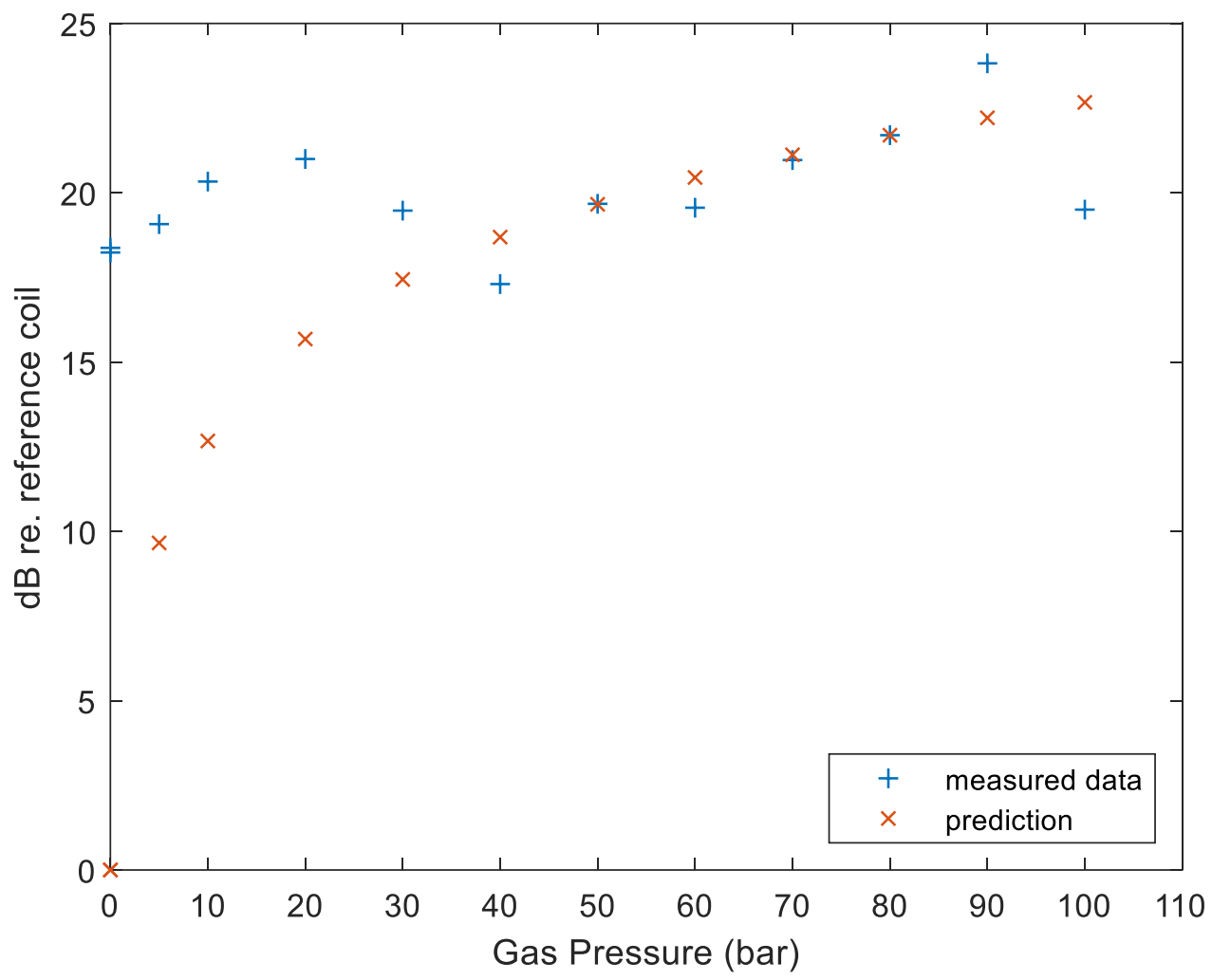

Figure 12

Total Vibrational Power vs Pressure for fibre position 5

Runs $1,11,15,19,23,25,38,42,40,35$ and 33: $3 \mathrm{~mm}$ side leak

Idealized jet flow theory suggests that the radiated noise from a gas jet can be attributed to quadrupole-type sources due to turbulent mixing in the shear layer [39]. The dimensional dependence of the radiated noise power, $W_{\text {quad }}$, is

$$
W_{\text {quad }} \sim \rho L^{2} u^{3} M^{5}
$$

where $\rho$ is the gas density, $L$ is an appropriate length scale (in this case the orifice diameter), $u$ is the jet velocity and $M$ is the jet Mach number.

In section 3 we showed that, for all the runs, the jet velocities and Mach numbers will be approximately the same. Thus for a single orifice diameter ( $3 \mathrm{~mm}$ in this case), the radiated noise power will be affected only by the upstream density (directly proportional to the 
upstream pressure, according to the ideal gas law, Equation 6). Plotted alongside the measured data in Figure 12 are predictions of the vibrational power, assuming a linear relationship with the pressure and a baseline pressure of 60 bar (in order to determine the constant of proportionality). It can be seen that, above 30-40 bar, there is reasonably good agreement between the measurements and predictions. Below 30 bar, the measured vibration becomes comparable with the background noise level (zero pressure on the plots), so no longer decreases with pressure as predicted.

\subsection{Effect of Leak Diameter}

The relationship of equation (10) indicates that, all other things being equal, the radiated sound power will be proportional to the square of the orifice diameter.

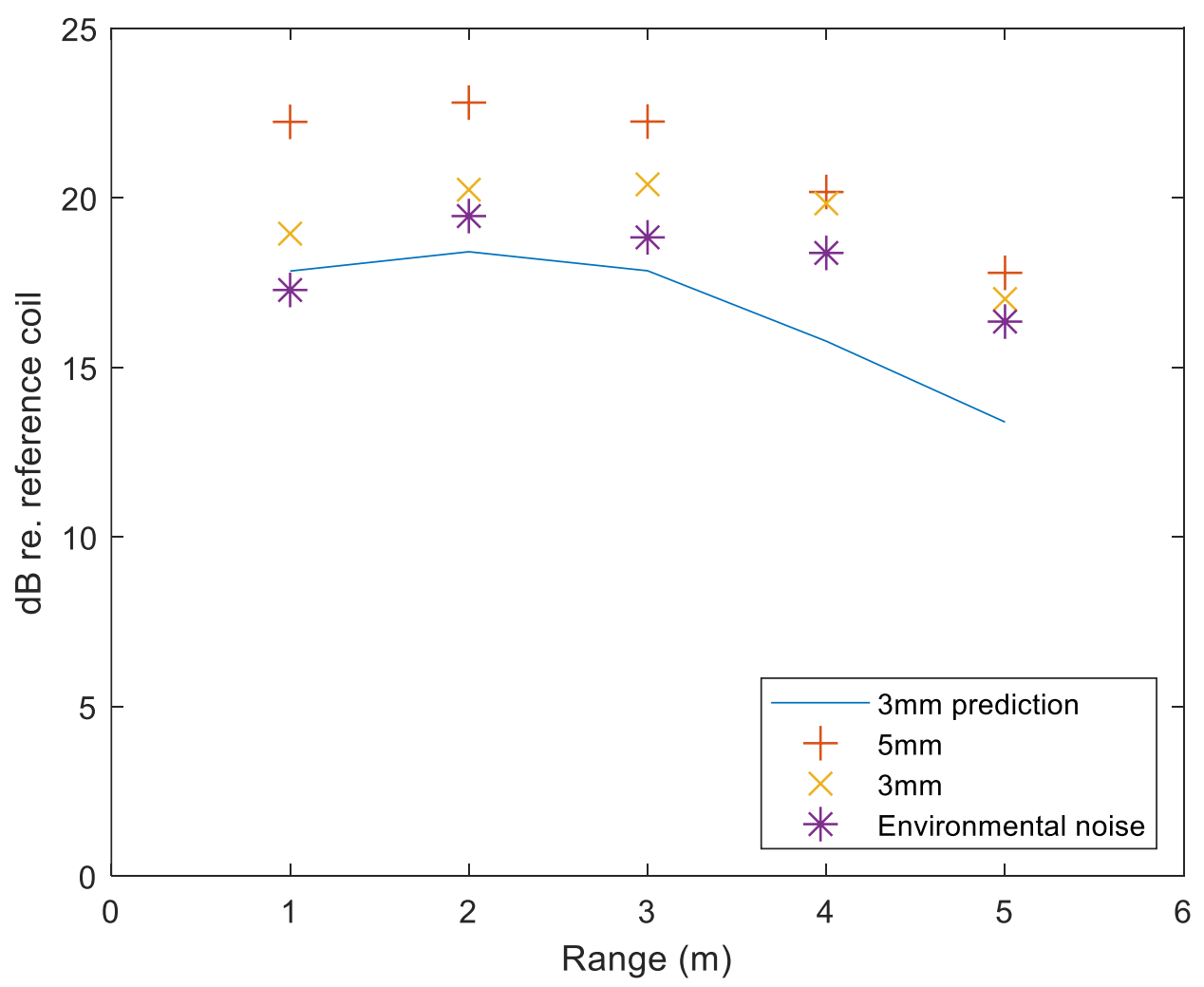

Figure 13

Total Vibrational Power vs Range for different leak sizes Runs 3 and 8: 100 bar 5mm down leak, 100 bar 3mm down leak 
Figures 13 depicts the measured vibrational power vs range for the $3 \mathrm{~mm}$ and $5 \mathrm{~mm}$ leaks pointing down. One can immediately see that the radiated power for the $5 \mathrm{~mm}$ leak is greater than that for the $3 \mathrm{~mm}$ leak at all ranges. According to equation (10), the total radiated power is proportional to the square of the orifice diameter. For $3 \mathrm{~mm}$ and $5 \mathrm{~mm}$ leak diameters, the $3 \mathrm{~mm}$ leak should therefore radiate approximately $4.4 \mathrm{~dB}$ less than the $5 \mathrm{~mm}$ leak. This prediction is also shown in the figure, in which it can be seen that, at small ranges, the level of agreement is fair, decreasing with increasing range. At ranges greater than $1 \mathrm{~m}$, the prediction brings the noise level for the $3 \mathrm{~mm}$ leak below the background noise level, thus invalidating the prediction.

Leak noise spectra for the $3 \mathrm{~mm}$ and $5 \mathrm{~mm}$ leaks are shown at 3 different ranges in Figures 14(a)-(c). At very low frequencies, below about $5 \mathrm{~Hz}$, the signal for the $5 \mathrm{~mm}$ leak is much larger than for the $3 \mathrm{~mm}$ leak; here, thermal effects are likely to dominate so the signal is not likely to be vibration-controlled. Above $5 \mathrm{~Hz}$, it can be seen that, at all three ranges, the shape of the spectra for the $3 \mathrm{~mm}$ and $5 \mathrm{~mm}$ leaks are similar, with the peak frequencies coinciding. Between $5 \mathrm{~Hz}$ and approximately $100 \mathrm{~Hz}$, the spectral magnitude of the $5 \mathrm{~mm}$ leak exceeds that of the $3 \mathrm{~mm}$ leak, with the largest differences being seen between at $1 \mathrm{~m}$ range and then the differences decreasing with range. By $4 \mathrm{~m}$ range, the magnitude of the $5 \mathrm{~mm}$ leak in this frequency region is almost equal to that of the $3 \mathrm{~mm}$ leak, suggesting that it is approaching the background noise level. Figure 13 shows that, at 4m, the leak noise for both sizes of leak is indeed within about $2 \mathrm{~dB}$ of the background noise. These findings suggest that most of the leak noise can be found at frequencies lower than $100 \mathrm{~Hz}$, in agreement with [23]. 


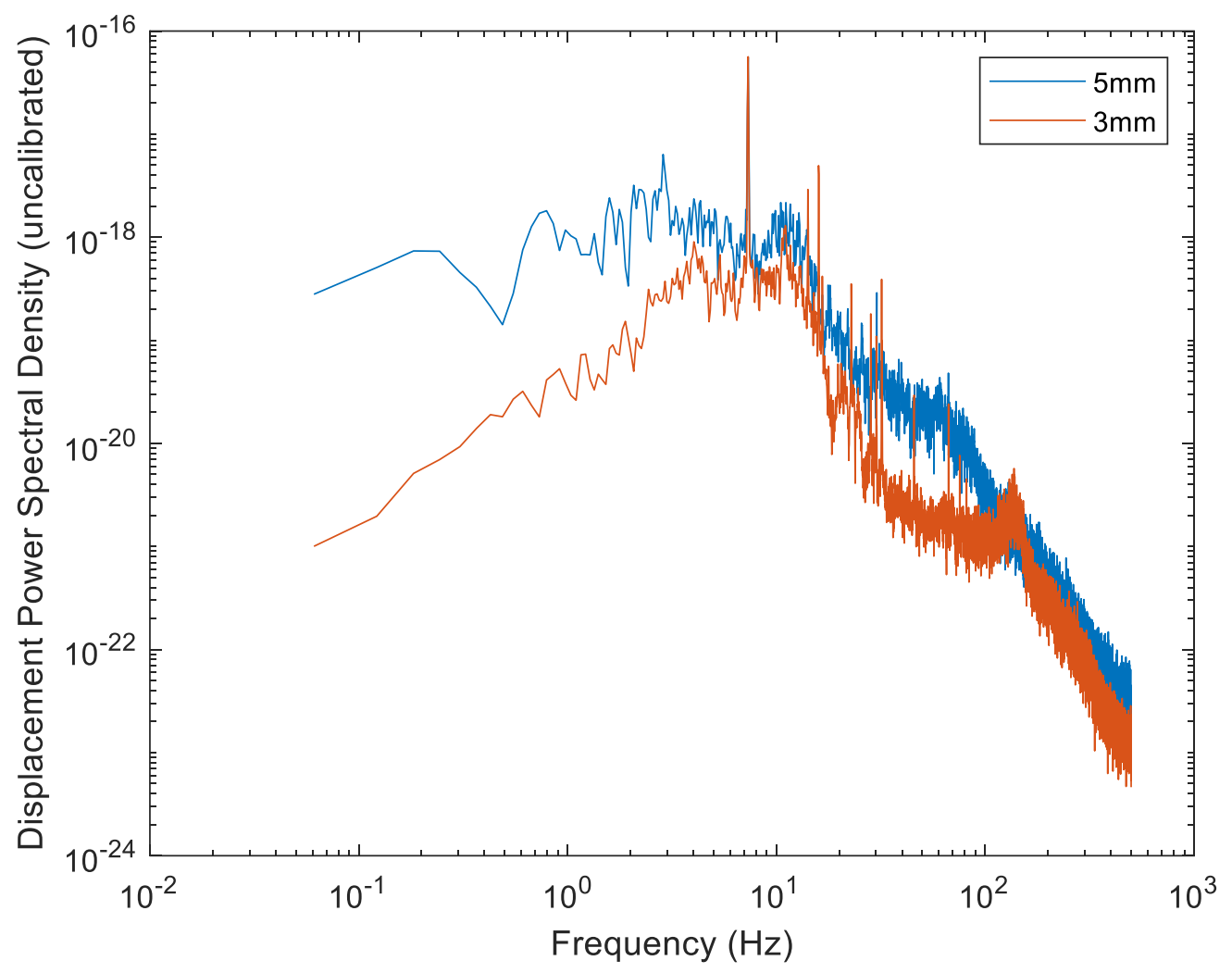

(a)

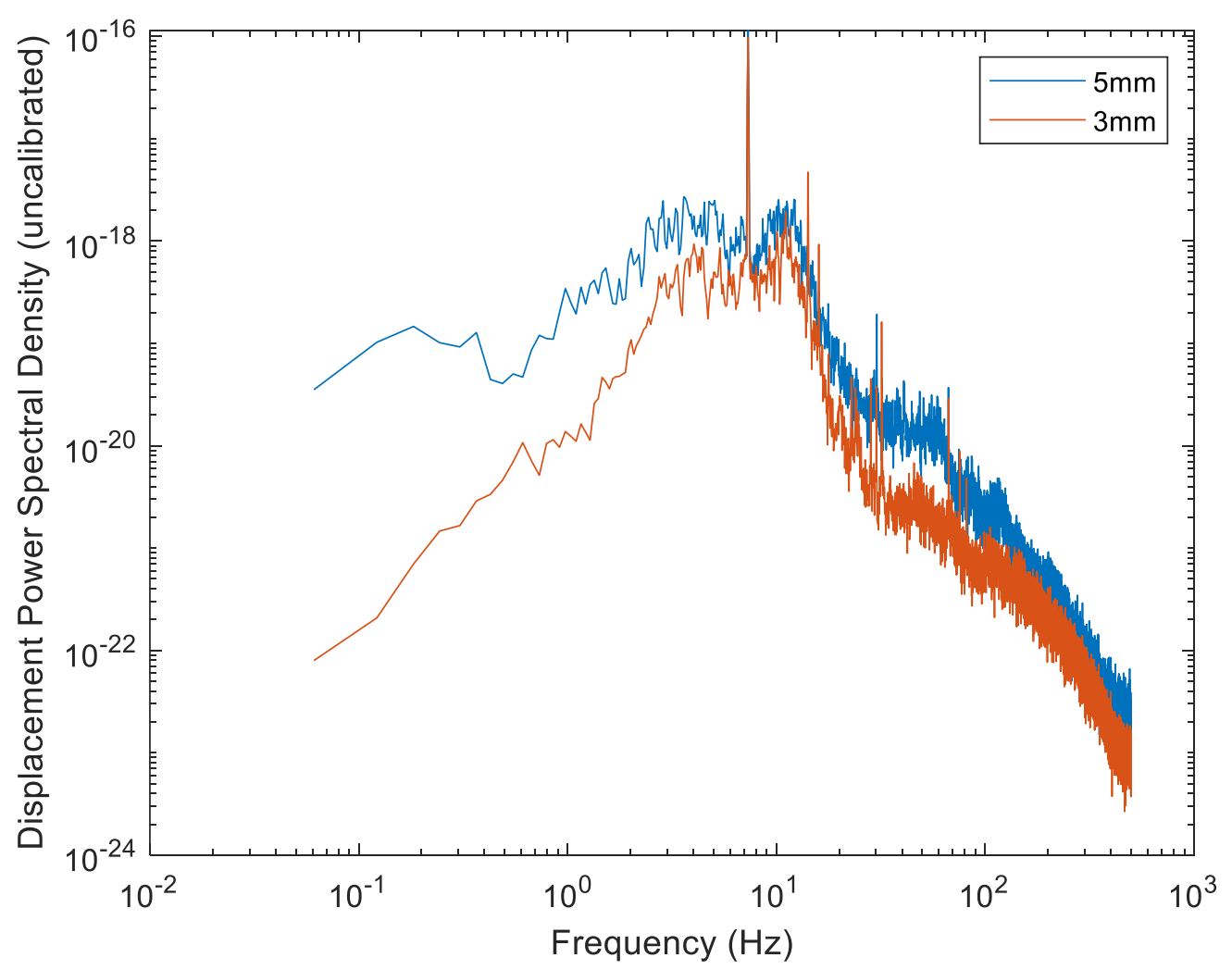

(b) 


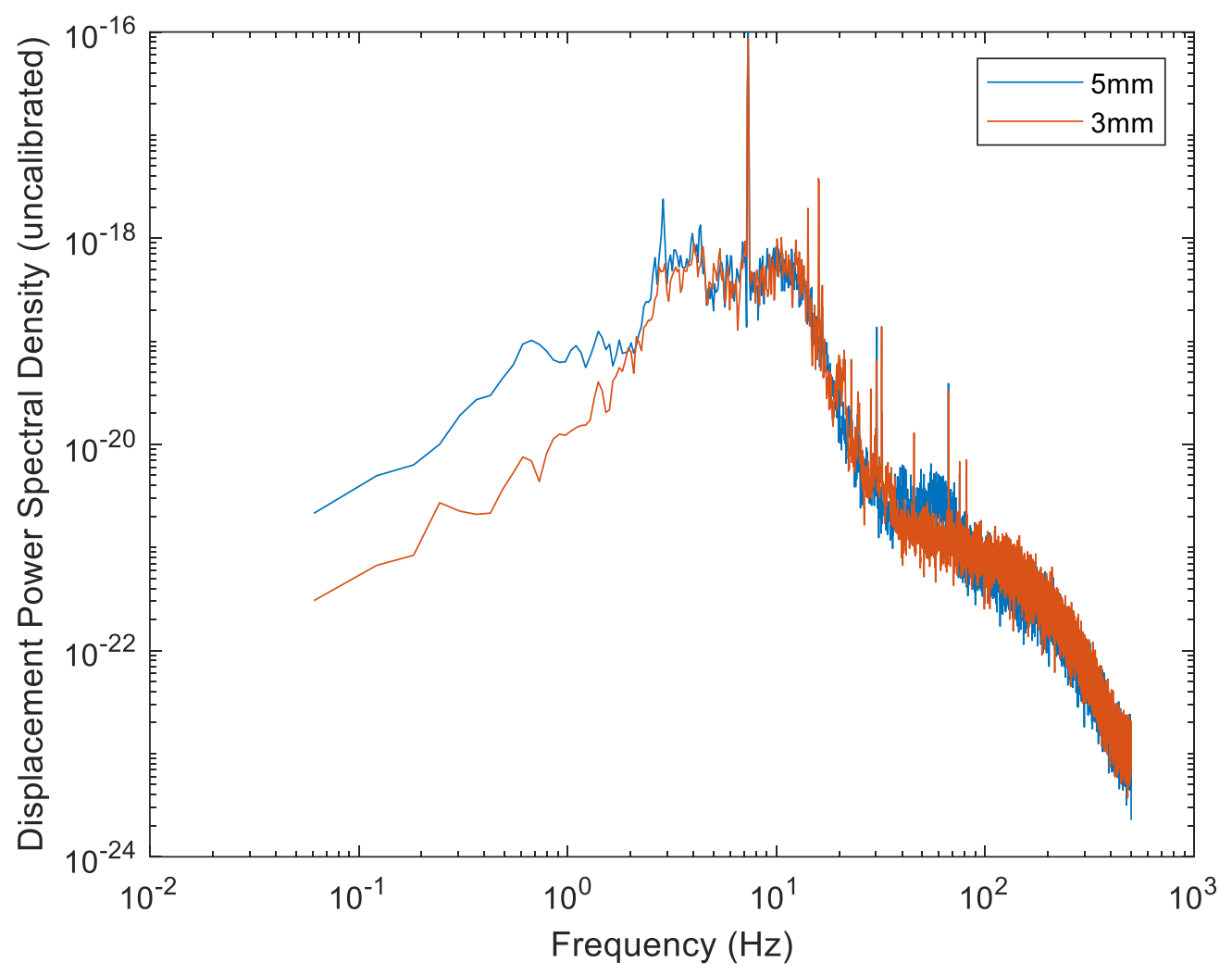

(c)

Figure 14

Displacement Power Spectra: Spectral comparisons between 5mm leak and 3m leak Runs 3 and 8: 100 bar, down

(a) fibre position 2, 1m; (b) fibre position 3,2m; (c) fibre position 5, 4m

\subsection{Effect of Leak Direction}

Figure 15 shows the effect of the leak direction on the total vibrational power for $5 \mathrm{~mm}, 100$ bar leaks. As expected, directly above the pipe at $0 \mathrm{~m}$ (fibre position 1 in Figure 5), the response is largest for the leak pointing upwards, followed by the side-directed leak, then the downward-pointing one. To the side of the pipe for all the fibre positions $(2,3,4,5$ and 6 , in Figure 5), the response is largest for the side leak. Again, this is as expected given the energy is being directed towards these measurement zones. That the response for the leak pointing upwards is less than that for the downward-pointing leak and, for the most part, similar to the 
background noise is, at first sight, surprising. It would be expected that that upward leak would set up sizeable surface waves, measurable in fibre positions 2-6. Whilst this might still be the case, the fact that the downward leak energy in these positions is larger suggests that the ground is markedly layered and that reflections within the layer enable this energy to propagate effectively. Unfortunately, it was not possible to ascertain if such ground layering was indeed present at the test site.

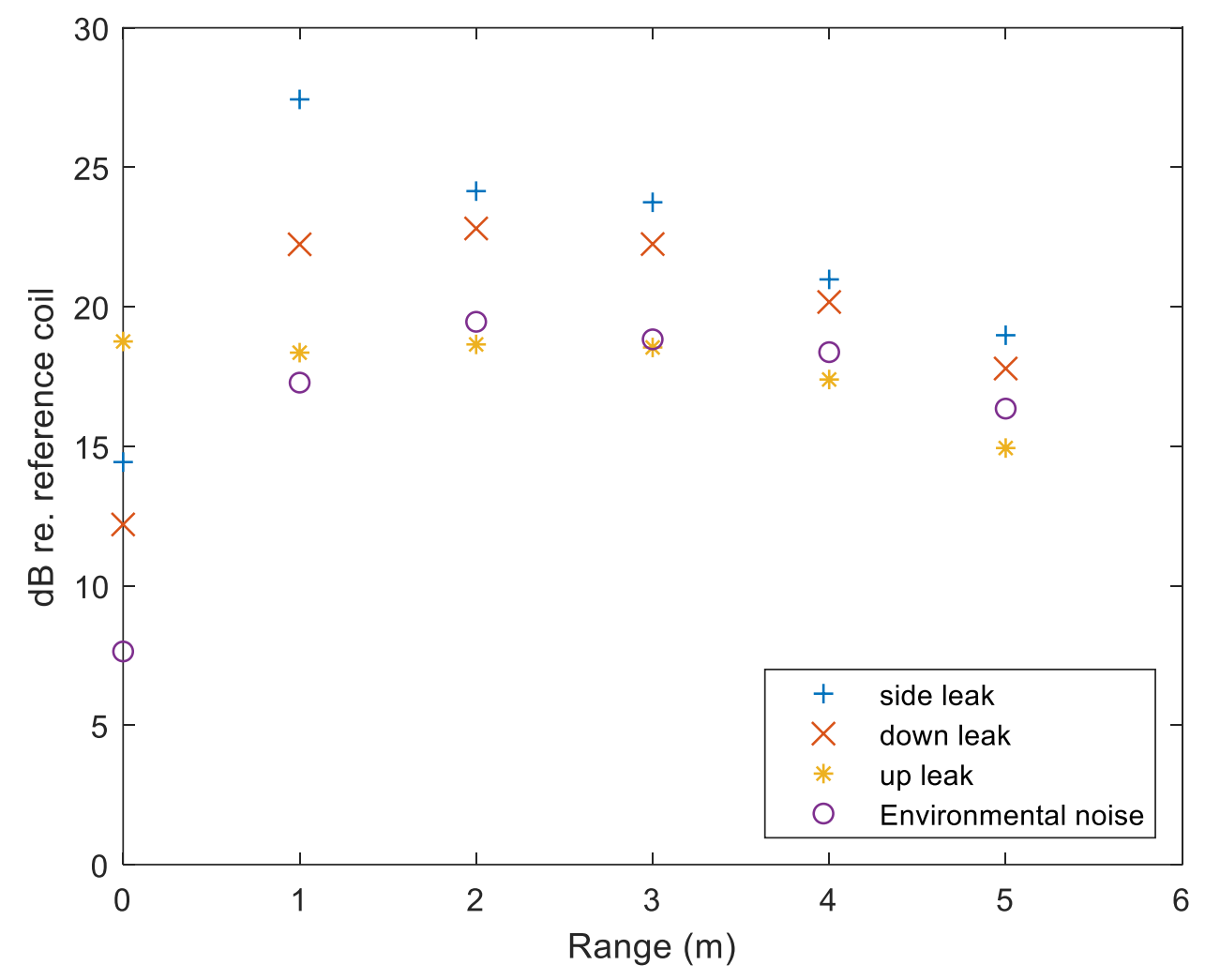

Figure 15

Total Vibrational Power (in $\mathrm{dB}$ relative to the reference coil) vs Range

Runs 6, 3 \& 9: 100bar 5mm side leak, down leak, up leak

\subsection{Effect of Fibre Ducting and Armouring}

In order to assess the effect of ducting and armouring on the fibre sensitivity, measured results from fibre position 7 (bare cable), 8 (armoured cable) and 9 (ducted cable) (see Figure 5) were compared. Nine tests at 100 bar comprising all combinations of leak orientation (up, 
side, down) and leak size (1mm, 3mm, 5mm) - test runs 1-9, Appendix I - were used for the comparison, along with an environmental noise measurement (run 0). Figure 16 shows the total vibrational power detected in each fibre position for the ten runs.

It can be seen that the measured response for the ducted cable is between about $3 \mathrm{~dB}$ and $8 \mathrm{~dB}$ lower than that measured on the bare cable. This is as might be expected given that the air in the ducting alongside the cable introduces an impedance boundary (the impedance being significantly different from that of both the surrounding soil and the cable) between the soil and the cable. That little difference between the armoured cable and the bare cable can be seen suggests that the armouring introduces no such boundary, whilst providing mechanical protection of the cable.

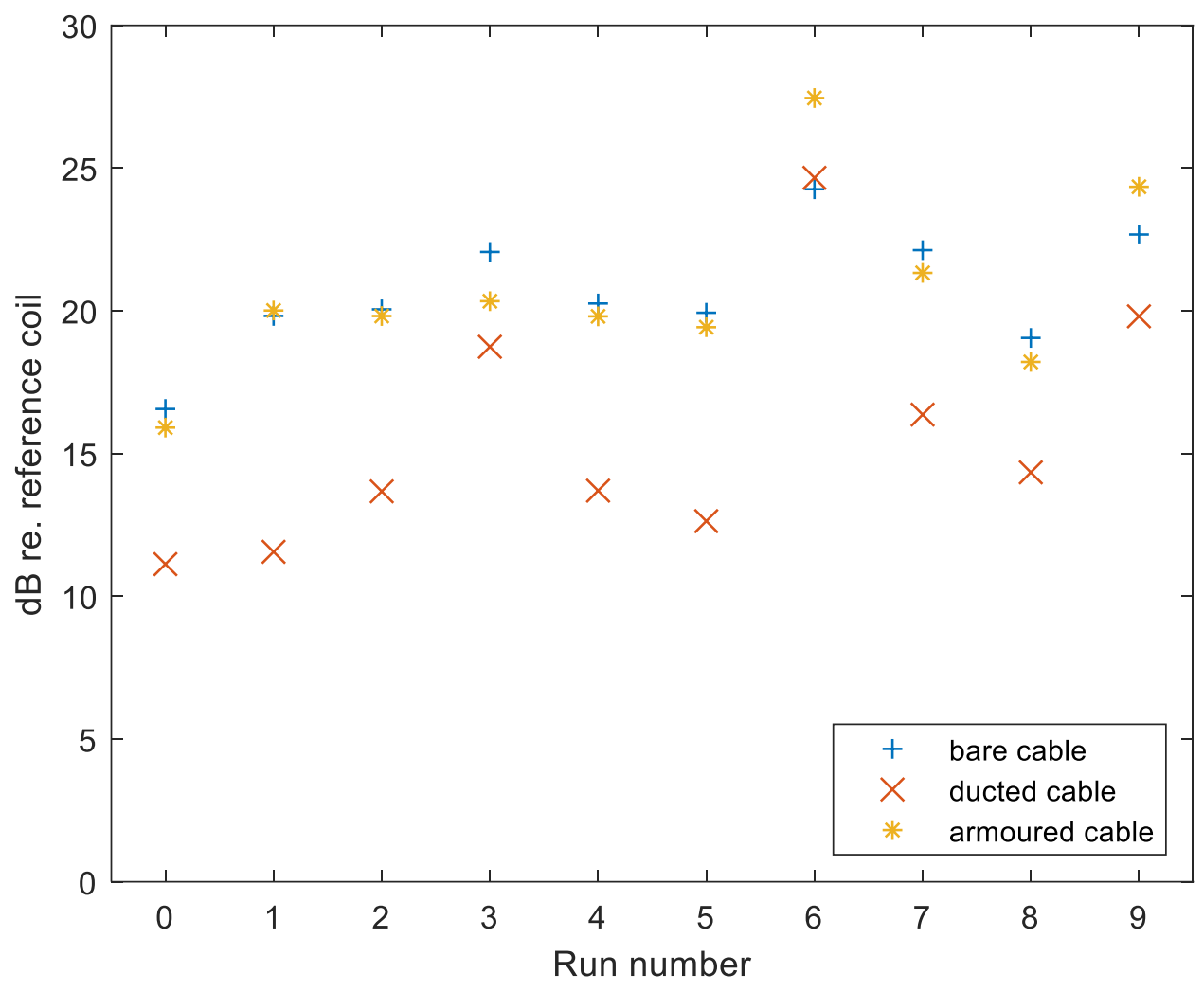

Figure 16

Total Vibrational Power for Different Runs 


\section{Conclusions and Future Work}

This paper has discussed the way in which a number of different key parameters affect the leak noise generated by a gas leak, also known as orifice noise (OFN). Results from a specially designed buried pipeline rig have been used so that one source of that leak noise dominates - the noise directly radiated from the leak orifice - whilst the other source (that mediated by the pipe wall through propagation along the pipe and thence into the soil) is, at least in part, suppressed. Distributed acoustic sensing using optical fibres was employed, along with geophones at the ground surface, to measure the vibration in the vicinity of the pipeline.

Both the geophones and the optical fibres were shown to be able to detect the orifice noise, particularly when the fibres were located close to the pipeline. At the measured frequencies (below $500 \mathrm{~Hz}$ for the fibre), it was found that the fibre responses had a higher noise level than geophones similarly located, particularly at the higher frequencies. Moreover, slightly more detail was evident in the geophone responses. Due to the relatively long gauge lengths used for the fibre (10m), all-important phase information, which could be used to determine wavespeeds, was lost. Wavespeeds estimated from the geophone data revealed two dominant wave types, propagating at around $100 \mathrm{~m} / \mathrm{s}$ and $250 \mathrm{~m} / \mathrm{s}$. These were considered to be the Rayleigh and compressional waves propagating in the soil.

Evaluating the effect of range, $r$, on the measured signal revealed a $1 / r^{0.5}$ dependence, suggesting that, as might be expected, the leak sets up Rayleigh waves which propagate along the ground surface away from the pipe. Evaluating the effect of the upstream gas pressure on the leak noise showed that, at least for the larger pressures, the overall noise power was proportional to this pressure, compatible with idealised jet theory. At the lower pressures the background noise was found to dominate. At short ranges, the radiated power was also found to be approximately proportional the square of the orifice diameter, as predicted. At the 
higher ranges, the agreement between the measurements and predictions were less good, again as a result of decreasing signal to noise ratios. The peaks in the leak noise spectra were found to be independent of leak diameter, with the largest magnitude differences between the leak size being at frequencies below $100 \mathrm{~Hz}$. This suggests that most of the leak noise is contained in frequencies below $100 \mathrm{~Hz}$, as found by previous authors. The findings regarding the effect of leak direction were inconclusive as it was not possible to confirm the ground layering on site. Finally, the effect of fibre ducting and armouring was evaluated. It was found that fibre ducting reduced the measured signals by between $3 \mathrm{~dB}$ and $8 \mathrm{~dB}$, due to the impedance mismatch between the fibre and the air in the duct and between the air in the duct and the surrounding soil. No such reduction was seen for the armoured cable, suggesting better impedance matching for the armour.

The environmental background noise was found to be a limiting factor for many of the measurements. Whilst the actual background noise in a live leak cannot be altered, for future research, three avenues are possible: firstly, to ensure that test measurements are undertaken in a quiet environment; secondly, to explore the background noise inherent in the optical fibres, with the aim of reducing it; and thirdly to seek to reduce the fibre gauge length such that phase measurements, more robust in the presence of noise [40], can be more gainfully employed. Finally, a valuable next step in this research programme would be the realisation of a second testing campaign, seeking to evaluate the characteristics of the leak noise propagated along the pipeline and thence radiated into the surrounding medium. It is likely that for these tests a more extensive test rig would be required.

\section{Acknowledgements}

The authors would like to acknowledge the financial support of AP Sensing to conduct the research presented here. Thanks are due to Dr Thomas Lauber and Dr Wissem Sfar Zaoui 
(AP Sensing $\mathrm{GmbH}$ ) for the design of the FOC setup and for conducting the experimental measurements.

\section{Appendix}

\section{Test Runs}

\begin{tabular}{|c|c|c|c|}
\hline Run Number & Leak diameter $(\mathrm{mm})$ & Leak direction & Test Pressure (bar) \\
\hline 1 & 3 & side & 100 \\
\hline 2 & 1 & down & 100 \\
\hline 3 & 5 & down & 100 \\
\hline 4 & 1 & up & 100 \\
\hline 5 & 3 & up & 100 \\
\hline 6 & 5 & side & 100 \\
\hline 7 & 1 & side & 100 \\
\hline 8 & 3 & down & 100 \\
\hline 9 & 5 & up & 100 \\
\hline 11 & 3 & side & 90 \\
\hline 15 & 3 & side & 80 \\
\hline 19 & 3 & side & 70 \\
\hline 23 & 3 & side & 60 \\
\hline 24 & 5 & up & 100 \\
\hline 25 & 3 & side & 50 \\
\hline 33 & 3 & side & 5 \\
\hline 35 & 3 & side & 10 \\
\hline 38 & 3 & side & 40 \\
\hline 40 & 3 & side & 20 \\
\hline 42 & 3 & side & 30 \\
\hline & & & \\
\hline
\end{tabular}

Table A1

Test Run Parameters

\section{References}

1. https://www.telegraph.co.uk/news/2019/01/19/least-20-killed-pipeline-explosion-centralmexico/

2. https://www.dailybulletin.com/2019/02/04/southern-california-gas-fined-3-3-million-forontario-pipeline-explosion/

3. https://www.al.com/business/2019/02/colonial-pipeline-suing-aig-over-explosionclaims.html 
4. H. V. Fuchs and R. Riehle, Ten years of experience with leak detection by acoustic signal analysis 1991 Applied Acoustics 33, 1-19.

5. Zhang, J., Hoffman, A., Murphy, K., Lewis, J., \& Twomey, M. (2013, April 16). Review of Pipeline Leak Detection Technologies. Pipeline Simulation Interest Group.

6. Pal-Stefan Murvay and Ioan Silea. A survey on gas leak detection and localization techniques, Journal of Loss Prevention in the Process Industries Volume 25, Issue 6, November 2012, Pages 966-973

7. Cuiwei Liu, Yazhen Wang, Yuxing Li, Minghai Xu, Experimental study on new leak location methods for natural gas pipelines based on dynamic pressure waves. Journal of Natural Gas Science and Engineering, Volume 54, June 2018, Pages 83-91

8. Arthur H Hartog, An Introduction to Distributed Optical Fibre Sensors. CRC Press 2017.

9. https://www.apsensing.com/application/pipeline-monitoring/

10. David Hill, Distributed Acoustic Sensing (DAS): Theory and Applications. Frontiers in Optics 2015, OSA Technical Digest (online) (Optical Society of America, 2015) paper FTh4E.1 $\underline{\text { https://doi.org/10.1364/FIO.2015.FTh4E.1 }}$

11. Tsubasa Sasakia, Jinho Park, Kenichi Soga, Taichi Momoki, Kyojiro Kawaguchi, Hisashi Muramatsu, Yutaka Imasato, Ajit Balagopal, Jerod Fontenot, Travis Hall, Distributed fibre optic strain sensing of an axially deformed well model in the laboratory. Journal of Natural Gas Science and Engineering, Volume 72, December 2019, 103028.

12. Yankun Sun, Ziqiu Xue, Tsutomu Hashimoto, Fiber optic distributed sensing technology for real-time monitoring water jet tests: Implications for wellbore integrity diagnostics. Journal of Natural Gas Science and Engineering, Volume 58, October 2018, Pages 241250. 
13. Worsley, J., Minto, C., Hill, D., Godfrey, A., \& Ashdown, J. (2014, November 10). Fibre Optic Four Mode Leak Detection for Gas, Liquids and Multiphase Products. Society of Petroleum Engineers. doi:10.2118/171824-MS

14. Maria-Teresa Hussels, Sebastian Chruscicki, Abdelkarim Habib, Katerina Krebber, Distributed acoustic fibre optic sensors for condition monitoring of pipelines. Proceedings Volume 9916, Sixth European Workshop on Optical Fibre Sensors; 99162Y (2016) https://doi.org/10.1117/12.2236809

15. Femi Tanimola and David Hill, Distributed fibre optic sensors for pipeline protection. Journal of Natural Gas Science and Engineering Volume 1, Issues 4-5, November 2009, Pages 134-143.

16. O. Hunaidi and W.T. Chu, Acoustical characteristics of leak signals in plastic water distribution pipes Applied Acoustics Volume 58, Issue 3, November 1999, Pages 235-254

17. Y. A. Khulief, A. Khalifa, R. Ben Mansour, and M. A. Habib. Acoustic Detection of Leaks in Water Pipelines Using Measurements inside Pipe, Journal of Pipeline Systems Engineering and Practice Volume 3 Issue 2 - May 2012

18. Papastefanou, Anastasia S.; Joseph, Phillip F.; Brennan, Michael J. Experimental Investigation into the Characteristics of In-Pipe Leak Noise in Plastic Water Filled Pipes, Acta Acustica united with Acustica, Volume 98, Number 6, November/December 2012, pp. $847-856$

19. Papastefanou, Anastasia S. An experimental investigation of leak noise from water filled plastic pipes, $P h D$ thesis, University of Southampton, 2011

20. Salvatore Belsito, Paolo Lombardi, Paolo Andreussi, Sanjoy Banerjee, Leak detection in liquefied gas pipelines by artificial neural networks. Process Systems Engineering 16 April 2004, https://doi.org/10.1002/aic.690441209 
21. Lingya Meng, Li Yuxing, Wang Wuchang, Fu Juntao. Experimental study on leak detection and location for gas pipeline based on acoustic method, Journal of Loss Prevention in the Process Industries Volume 25, Issue 1, January 2012, Pages 90-102

22. A. Ebrahimi-Moghadam, M. Farzaneh-Gord, M. Deymi-Dashtebayaz. Correlations for estimating natural gas leakage from above-ground and buried urban distribution pipelines. Journal of Natural Gas Science and Engineering, Volume 34, August 2016, Pages 185196.

23. J M Muggleton, M J Brennan and R J Pinnington. Wavenumber prediction of waves in buried pipes for water leak detection, Journal of Sound and Vibration 249(5), 2002, 939954.

24. J.M. Muggleton, M.J. Brennan and P.W. Linford, Axisymmetric wave propagation in fluid-filled pipes: wavenumber measurements in in-vacuo and buried pipes, Journal of Sound and Vibration 270 (2004) 171-190

25. J.M. Muggleton and M.J. Brennan, Leak noise propagation and attenuation in submerged plastic water pipes. Journal of Sound and Vibration 278 (2004) 527-537.

26. Y Gao, M J Brennan, P F Joseph, J M Muggleton and O Hunaidi. A model of the correlation function of leak noise in buried plastic pipes, Journal of Sound and Vibration 277 (2004), 133-148.

27. J M Muggleton and M J Brennan, Axisymmetric wave propagation in buried, fluid-filled pipes: effects of wall discontinuities. Journal of Sound and Vibration 281 (2005) 849867.

28. Y Gao, M J Brennan, P F Joseph, J M Muggleton and O Hunaidi. On the selection of acoustic/vibration sensors for leak detection in plastic water pipes. Journal of Sound and Vibration 283 (2005), 927-941. 
29. J M Muggleton and Jin Yan, Wavenumber prediction and measurement for buried fluidfilled pipes: inclusion of shear coupling at a lubricated pipe/soil interface. Journal of Sound and Vibration, 332(5) (2013), 1216-1230.

30. Muggleton, Jennifer, Kalkowski, Michal, Gao, Yan and Rustighi, Emiliano. A theoretical study of the fundamental torsional wave in buried pipes for pipeline condition assessment and monitoring. Journal of Sound and Vibration, 374 (2016), 155-171

31. Gao, Yan, Sui, Fusheng, Muggleton, Jennifer and Yang, Jun, Simplified dispersion relationships for fluid-dominated axisymmetric wave motion in buried fluid-filled pipes. Journal of Sound and Vibration, 375 (2016), 386-402.

32. Yan Gao, Jennifer M. Muggleton, Yuyou Liu, Emiliano Rustighi, An analytical model of ground surface vibration due to axisymmetric wave motion in buried fluid-filled pipes. Journal of Sound and Vibration 395 (2017), 142-159.

33. Michał K. Kalkowski, Jennifer M. Muggleton, Emiliano Rustighi, Axisymmetric semianalytical finite elements for modelling waves in buried/submerged fluid-filled waveguides. Computers and Structures, 196 (2018), 327-340.

34. M.J. Brennan, M. Karimi, J.M. Muggleton, F.C.L Almeida, F. Kroll de Lima, P.C. Ayala, D. Obata, A.T. Paschoalini, N. Kessissoglou, On the Effects of Soil Properties on Leak Noise Propagation in Plastic Water Distribution Pipes. Journal of Sound and Vibration 427 (2018), 120-133.

35. Marc Baqué, Fibre Optic Leak Detection FOLD Project, Society of Petroleum Engineers SPE 183137-MS (2016).

36. Gas Pipeline Incidents. 8th Report of the European Gas Pipeline Incident Data Group, EIG 11.R.0402 (version 2) December 2011. Available at www.egig.eu 
37. Zhengqing Pan, Kezhen Liang, Qing Ye, Haiwen Cai, Ronghui Qu, Zujie Fang, "Phasesensitive OTDR system based on digital coherent detection," Proc. SPIE 8311, Optical Sensors and Biophotonics III, 83110S (29 November 2011)

38. https://en.wikipedia.org/wiki/Choked_flow

39. Leo L. Beranek (ed.), Noise and Vibration Control. McGraw-Hill Book Company, New York, 1971, ch. 16.

40. J M Muggleton, M J Brennan and Y Gao, Determining the location of underground plastic water pipes from measurements of ground vibration. Journal of Applied Geophysics, 75 (2011) 54-61. 